\title{
U.S. DEPARTMENT OF HEALTH AND HUMAN SERVICES
}

Agency for Toxic Substances and Disease Registry,

Division of Toxicology and Human Health Sciences,

Environmental Health Surveillance Branch, Atlanta, Georgia

\section{NATIONAL TOXIC SUBSTANCE INCIDENTS PROGRAM (NTSIP) ANNUAL REPORT 2011}

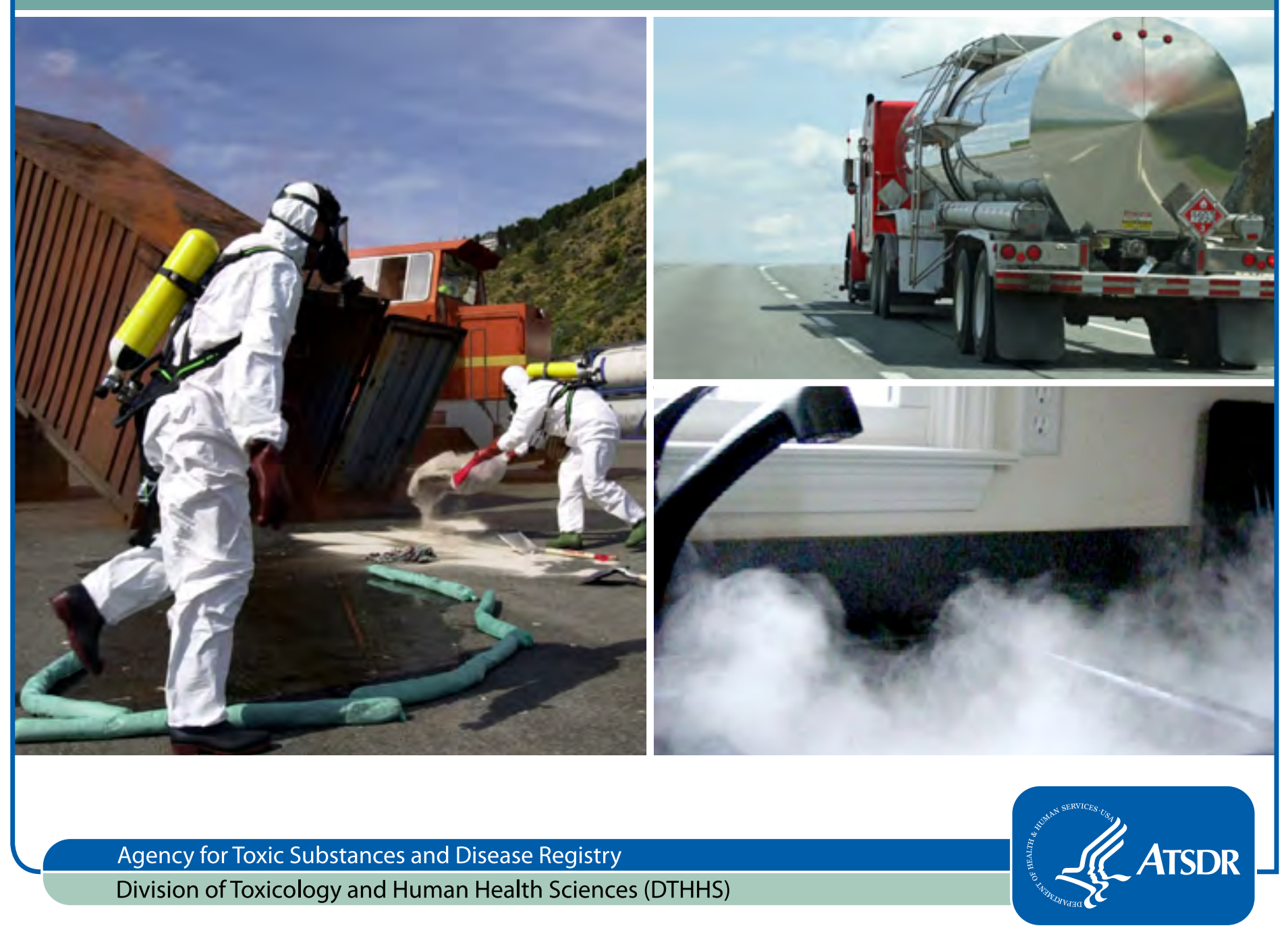


In 1980, Congress created the Agency for Toxic Substances and Disease Registry (ATSDR) to implement health-related sections of laws that protect the public from hazardous wastes and environmental spills of hazardous substances. The Comprehensive Environmental Response, Compensation, and Liability Act of 1980 (CERCLA), commonly known as the Superfund Act, designated ATSDR as the lead agency within the U.S. Public Health Service to help prevent or reduce further exposure to hazardous substances and the adverse health effects that might result from such exposures and to expand the knowledge base about such effects.

In accordance with CERCLA and SARA mandates, this publication reports results and findings of health studies, registries, or other health-related activities supported by ATSDR

Comments regarding this report are welcome. Please send your comments to the following address

Agency for Toxic Substances and Disease Registry

Attn: Chief, Environmental Health Surveillance Branch, DTHHS

4770 Buford Highway, Mailstop F-58, NE Atlanta, Georgia 30341 


\section{Table of Contents}

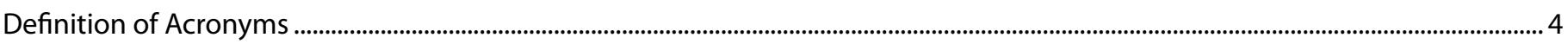

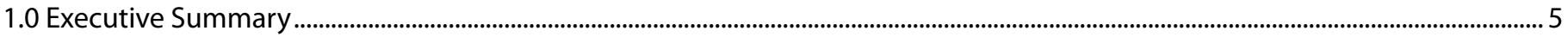

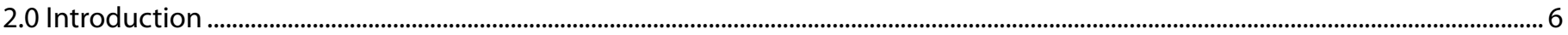

2.1 Historical Perspective and Background.............................................................................................................................................. 6

3.0 State Surveillance

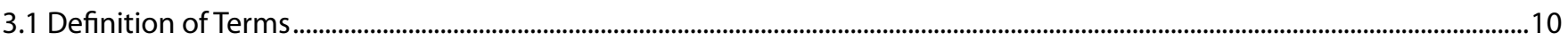

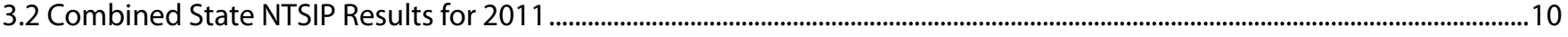

3.21 Showcasing State Impact Through Project Highlights ...............................................................................................................10

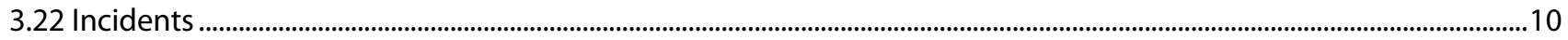

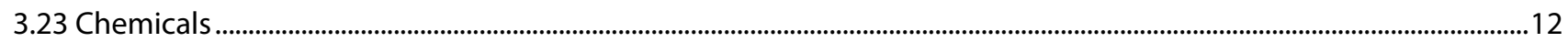

3.24 Factors Contributing to Incidents..............................................................................................................................................15

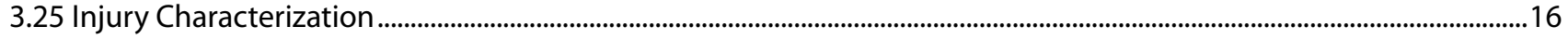

3.26 Response and Evacuation ..........................................................................................................................................................17

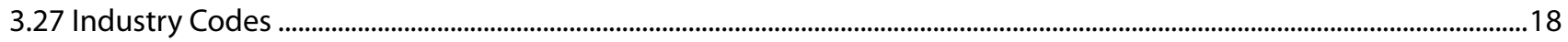



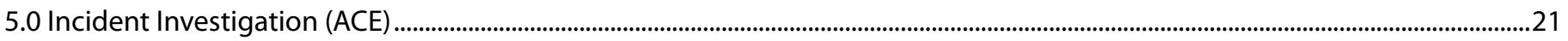

5.1 Chlorine Gas Release at a Chicken Processing Plant in Arkansas: An ACE Investigation Conducted with NIOSH ..............21

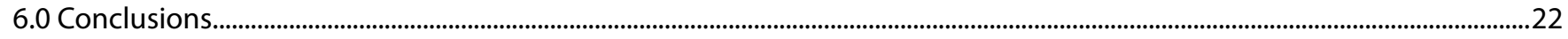

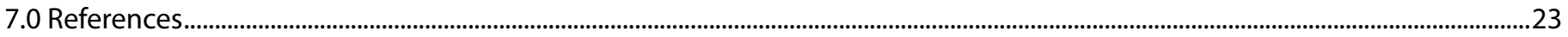

Appendix 


\section{Definition of Acronyms}

\section{Acronym}

\section{ACE}

ADH

ATSDR

CDC

CNS

DOT

EMS

EPA

HAZMAT

HHE

HIP

HMIS

HSEES

IRIS

LEPC

NAICS

$\mathrm{NIOSH}$

NRC

NTSIP

OSHA

PPE

RMP

\section{Definition}

Assessment of Chemical Exposures

Arkansas Department of Health

Agency for Toxic Substances and Disease Registry

Centers for Disease Control and Prevention

Central Nervous System

Department of Transportation

Emergency Medical Services

Environmental Protection Agency

Hazardous Materials

Health Hazard Evaluation

Hazmat Intelligence Portal

Hazardous Material Information System

Hazardous Substances Emergency Events Surveillance

Integrated Risk Information System

Local Emergency Planning Committee

North American Industry Classification System

National Institute of Occupational Safety and Health

National Response Center

National Toxic Substance Incidents Program

Occupational Safety and Health Administration

Personal Protective Equipment

Risk Management Program 


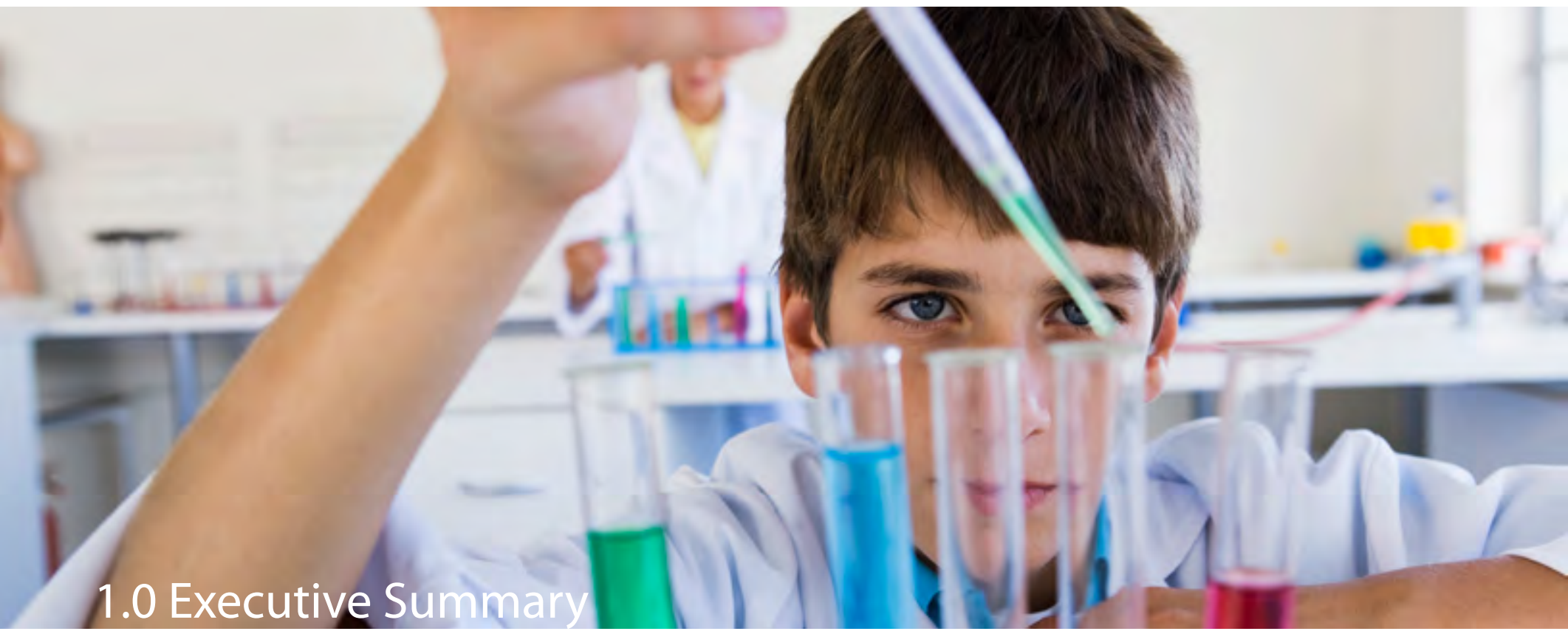

This Annual Report documents the second year of the National Toxic Substance Incidents Program (NTSIP), the only chemical surveillance system currently in existence that collects information on key aspects of acute hazardous chemical incidents. The purpose of this program is threefold:

1. Build capacity at state health departments to establish and maintain a program that collects information on chemical spills, identifies vulnerable populations by using mapping tools, creates and implements community intervention strategies, incorporates green chemistry initiatives, and enhances chemical exposure knowledge.

2. Establish a comprehensive national chemical incident database through the maintenance of a data repository that incorporates the states' data with supplemental data from the National Response Center (NRC) and the Department of Transportation (DOT) to create national chemical incident estimates and use these national estimates to monitor trends and publish information about relevant chemical exposure prevention.

3. Support large-scale chemical incident investigations through Assessment of Chemical Exposure (ACE) teams and develop resource materials that can be used at the state level to support smaller-scale chemical incidents; data and information gathered from these investigations aid in promoting emergency response and preparedness activities and in creating a cohort of exposed people who can be followed up with as a means of studying long-term health effects.

This document reports detailed results of the federal and state programs' efforts in 2011.

The following are key findings of the analysis:

- In 2011, 3,128 NTSIP incidents occurred in fixed facilities and during transportation, resulting in 1,177 injured persons, of which 62 were fatalities.

- More incidents, injuries, and fatalities occurred in fixed facilities than during transportation; fixed facility incidents accounted for $69.1 \%$ of all incidents, $90.1 \%$ of injuries, and $64.5 \%$ of fatalities.

- The top 20 chemicals in fixed facility incidents accounted for more than half ( $\mathrm{n}=1273,58.9 \%$ ) of all reported incidents; in transportation-related incidents, the top 10 chemicals accounted for just over a third of all incidents $(\mathrm{n}=318,33.2 \%)$.

- A total of 608 persons were injured as a result of exposure to four chemicals: carbon monoxide $(\mathrm{n}=256)$, illicit methamphetamine production chemicals $(n=78)$, paints and dyes $(n=61)$, and petroleum $(n=205)$. 
- Equipment failure and human error resulted in the largest number of incidents and injuries; equipment failure was responsible for 1,356 incidents and 448 injuries, while 1,317 incidents and 421 injuries were a result of human error.

- About half of all injuries ( $\mathrm{n}=603,51.2 \%$ ) occurred among the general public.

- Respiratory system problems were the single adverse health effect reported most frequently (21.8\%); other adverse health effects were dizziness or other CNS symptoms (17.7\%) and burns (13.1\%). About $22.8 \%$ of injured people reported experiencing multiple adverse health effects.

- An evacuation was ordered in $18.6 \%$ of incidents, while $2.3 \%$ of incidents resulted in a sheltering-in-place order.

Instances in which states have observed a need for or gap in information and developed an activity to meet that need or gap are highlighted throughout the results section as stories of impact. The impact stories summarized in this annual report show both the depth and the variety of a program's activities. Because each state program creates activities that focus on issues pertinent to the state, such programs are designed to find innovative solutions as a means of proactively assisting emergency management and responders by providing them with the necessary information to reduce the effects of a chemical spill.

The NTSIP national database uses reported incidents from seven funded states, in conjunction with other national chemical incident and injury databases (including NRC and DOT), to estimate the number of NTSIP qualifying chemical incidents occurring in all states that do not report to NTSIP. In 2011, 15,972 total NTSIP qualifying incidents were estimated to have occurred across the United States; 10,498 incidents were estimated to have occurred in fixed facilities, while 5,474 incidents were estimated to be transportation-related. ATSDR continues to research and acquire data to supplement NTSIPreported data, strengthening the ratios used to estimate incidents in non-reporting states (see Section 4.0, National Database, to learn how national estimates are derived, view the estimates for 2011, and see the comparisons between the 2010 and 2011 estimates). The ability to provide better estimates of chemical incidents on a national scale allows states to be more proactive in their response.

The ACE team is a resource for states to use when large-scale spills occur. The team can aid in the collection and documentation of information relevant to an incident by deploying to assist the state or supplying a tool kit of resources that the state can use when collecting data. Data collected from such incidents can be used to develop publications and presentations in which lessons learned can be shared for future incident planning. In 2011, the ACE team collaborated with the National Institute of Occupational Safety and Health (NIOSH) on an event at a chicken processing plant in Arkansas where chlorine gas was released, potentially exposing 600 employees working at the time of the release. For additional details regarding the spill, including the number of workers exposed, the survey conducted by the ACE team, and lessons learned through this event, refer to Section 5.1, Chlorine Gas Release at a Chicken Processing Plant in Arkansas: An ACE Investigation Conducted with NIOSH.

\subsection{Introduction}

\subsection{Historical Perspective and Background}

As chemical manufacturing, production, transportation, and use continue to increase across the United States [1], the likelihood of communities being affected by chemical spills increases as well. The need has never been greater for a comprehensive chemical surveillance program to permit a better understanding of why chemical spills occur, along with the need to use data on adverse effects on affected communities as a means of preventing future incidents. The National Toxic Substance Incidents Program (NTSIP) was established to address such needs.

NTSIP is an acute national chemical surveillance program that was established in January 2010 to replace the Hazardous Substance Emergency Events Surveillance (HSEES) Program, which had existed since 1990. NTSIP collects and combines information from many sources to protect populations from harm caused by acute toxic substance releases. Participating states gather specific information on chemical incidents-location of incident, evacuation details, number of injured persons, adverse health effects experienced by those injured or exposed-and enter the information into a Web-based database. Such information can be used to prevent or reduce the morbidity and mortality caused by these types of chemical incidents as well as to assist in proactively planning for future chemical incidents.

While the concepts and fundamental principles of NTSIP have been described in detail previously [2], specific aspects of the program are reviewed below. NTSIP is based upon three components: (1) state surveillance, (2) a national database, and (3) the Assessment of Chemical Exposures (ACE) team. Table 1 provides a summary description of each component and its core function, as well as the relevant stakeholders. 


\section{Table 1. Summary information on the three primary components of NTSIP.}

\section{Component Description}

Component Description

- Collect data on chemical incidents as well as information on toxic substance use and transport occurring within the state

- Use data and mapping tools to identify and prioritize areas and populations vulnerable to specific types of chemical incidents

- Provide data by which emergency response teams, local emergency planning committees, state and local health departments, and police and fire departments can proactively prepare for chemical incidents by knowing the types of vulnerable populations (i.e., schools, daycare and nursing home facilities, and residences) in the area, as well as by mapping out evacuation routes and the fastest access to hospitals

\section{Stakeholders} State Surveillance
- Funded States
- Louisiana
- New York
- North Carolina
- Oregon
- Tennessee
- Utah
-Wisconsin

\section{Core Functions}

Perform prevention outreach activities within the three-year award cycle; in the 2011 cycle, the focus is on green chemistry initiatives as well as on a reduction in the release of toxic chemicals to be achieved by education about inherently safer technologies. Also, analyze data trends on an annual basis and develop prevention outreach programs aimed at decreasing the morbidity and mortality associated with acute chemical exposures.

National Database

- Collaborate with various federal and state agencies to combine existing data from the NRC's Incident Reporting Information System (IRIS) and the DOT's Hazardous Materials Identification System (HMIS) with the NTSIP state surveillance data

- Housed within the DOT Hazmat Intelligence Portal (HIP)

$$
\begin{aligned}
& \text { - Existing Partnerships } \\
& \text { - ATSDR } \\
& \text { - DOT } \\
& \text { - NRC } \\
& \text { - State Health Departments }
\end{aligned}
$$

- Can be used by federal, state, and local agencies, emergency responders, and researchers for preparedness planning activities.

- NTSIP continues to explore chemical incident and injury data from additional sources so that the ability to estimate chemical spill incidents will improve on a national scale.

- Used to monitor trends and publish information regarding exposure prevention.

\section{Assessment of Chemical Exposures (ACE) team}

- Can provide a variety of services to the state or local government, including

- Increasing the personnel available for response to a situation affecting public health

- Streamlining access to CDC subject matter experts and laboratory resources

- Facilitating the coordination of multi-stage investigations

- Providing tool-kit to increase state capacity to conduct an assessment of the incident
- State Health Departments

- Local Health Departments

- National Institute of Occupational Safety and Health (NIOSH)

- Occupational Safety and Health Administration (OSHA)

- Emergency response management and personnel teams

- Chemical Safety and Hazard Investigation Board (CSB)

- National Institute for Environmental Health Sciences
- During a field investigation, the ACE team collects information through interviews administered to key response personnel (i.e., local fire department staff, HAZMAT first responders, environmental health officers, hospital staff, business owners, and employees).

- These key informant interviews create a structured timeline of the incident.

- A survey is administered to people who were in the exposed release area.

- All data collected through the administration of the surveys are entered into a database so that preliminary analysis can be performed in the field to provide relevant information to the requesting agency as quickly as possible.

- Medical charts are abstracted for treated persons.

- Findings from ACE investigations are published to expand chemical exposure knowledge. 
Many agencies and organizations collect information on chemical incidents, including the CSB, the National Transportation Safety Board, the DOT, ATSDR, OSHA, EPA's Risk Management Program (RMP) and Accidental Release Incident Program, the National Fire Incident Reporting System, and the Department of Energy (DOE); however, these organizations and agencies collect data relevant only to their individual priorities. For example, NIOSH is interested in data on chemical exposures that occur in occupational environments. Some pieces of data are being reported numerous times, while some data are not reported at all; additionally, the information is spread across many different databases, rendering the information difficult to access quickly.
In order to understand the importance of a comprehensive chemical database, one must first understand the number of these types of spills that occur on a yearly basis. Researchers have estimated that between 25,000 and 35,000 incidents involving chemicals occur annually. These incidents are broader than the three component areas of the NTSIP; ATSDR estimates that there are approximately 16,000 incidents annually using the NTSIP definition alone. It is further estimated that among those 25,000-35,000 incidents, approximately 5,000 injuries occur. Of reported injuries, between 500 and 1,000 are considered serious, resulting in an overnight stay in the hospital. Finally, a fraction of all serious injuries (between 100 and 500) results in a fatality. These estimations are represented in the chemical incident hierarchy shown in Figure 1.

\section{0-150 fatalities resulting from} incidents

\section{0-1,000 serious injuries resulting from incidents}

\section{5,000 injuries resulting from incidents}

\section{$25,000-35,000$ chemical incidents}

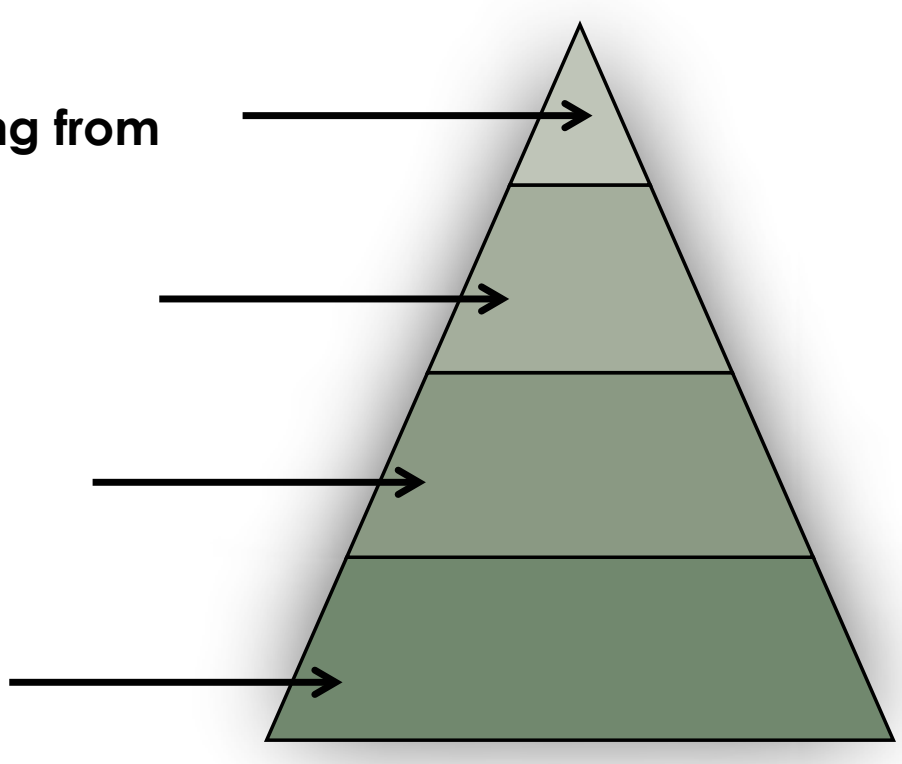

Figure 1. Tiered hierarchy of chemical incidents occurring in the United States annually [3, 4]. 


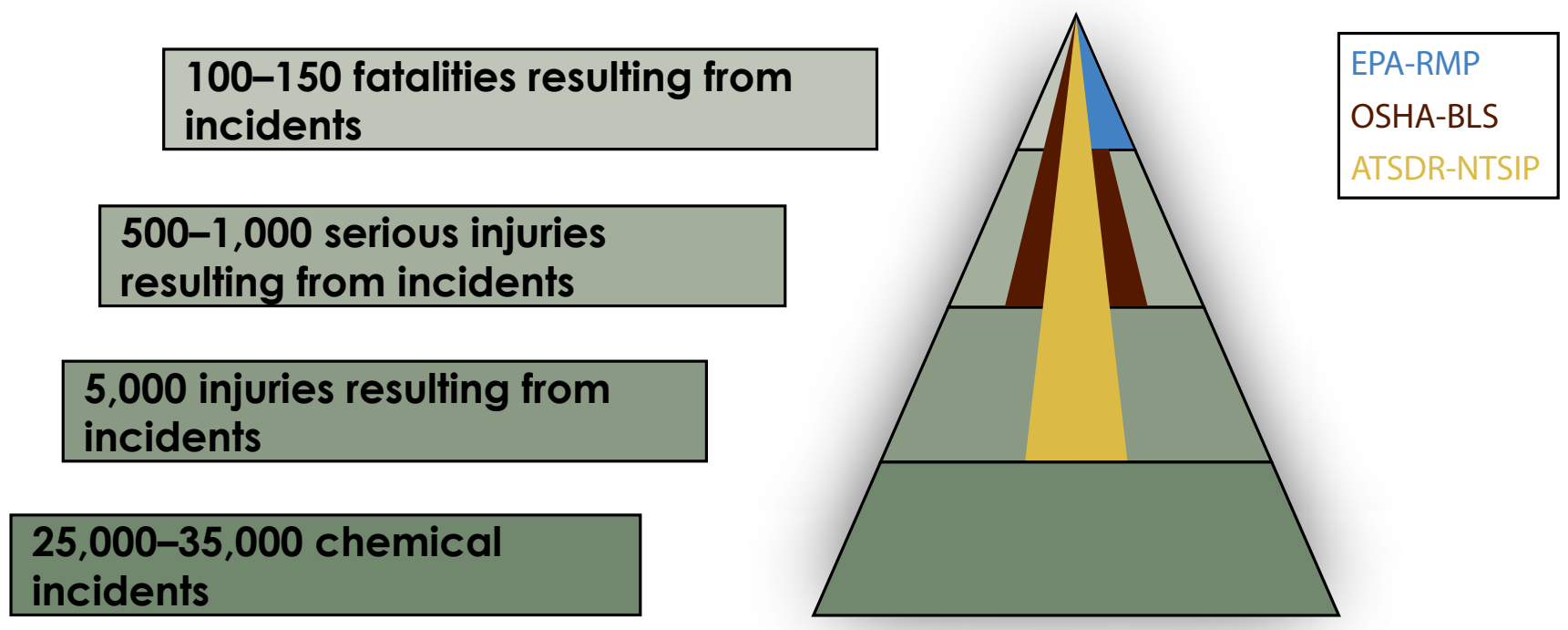

Figure 2. The completeness of data on chemical incidents collected by various agencies and organizations interested in chemical surveillance [3, 4].

One way NTSIP collects chemical information is through continued state surveillance. We provide additional information on the state surveillance component of NTSIP in the following section. The information includes the chemical(s) involved in a release, the quantity(ies) released, evacuations, public health actions, injuries, and deaths. Stakeholders use NTSIP data to better prepare and respond to future chemical spill incidents.

\subsection{State Surveillance}

In 2011, NTSIP continued to partner with state health departments to build surveillance capacity, establish and maintain data reporting partnerships, identify vulnerable populations by using mapping tools, develop and implement community intervention strategies, and enhance chemical exposure knowledge. In 2011, seven states participated in the cooperative agreement with NTSIP to report chemical incidents in their states; these states were Louisiana, New York, North Carolina, Oregon, Tennessee, Utah, and Wisconsin.
States monitor chemical incidents through a variety of sources. Data-sharing partners available to reporting states include the state DOT's HIP, the state and national Poison Control Center, the NRC, the state Department of Natural Resources, local health departments, local emergency planning committees (LEPCs), the state Department of Agriculture, the state Division of Emergency Management, the media, regional epidemiologists, the state police, and the state bureaus of investigation. Each state develops data-sharing agreements with the organizations most responsible for addressing the types of incidents reported in its state. These partnerships are synergistic, because the state develops a network of stakeholders from which to obtain incident data and in turn shares annual incident data with its stakeholders. 


\subsection{Definition of Terms}

In order to allow full interpretation of the results discussed in this report, we provide the following definitions in Table 2 :

\begin{tabular}{|l|l|}
\hline \multicolumn{2}{|c|}{$\begin{array}{l}\text { Table 2. Important definitions for interpreting } \\
2011 \text { NTSIP results. }\end{array}$} \\
\hline Term & Definition \\
\hline NTSIP incident & Any acute, uncontrolled, or illegal acute release of any toxic substance meeting NTSIP reporting criteria.* \\
\hline toxic substance & $\begin{array}{l}\text { Any element, substance, compound, or mixture, including disease-causing agents, where inhalation, or assimilation } \\
\text { into any organism, either directly from the environment or indirectly by ingestion through the food chain, will or may } \\
\text { reasonably be anticipated to cause death, disease, behavioral abnormalities, cancer, genetic mutation, physiological mal- } \\
\text { formations, including malformations in reproduction, or physical deformation in such organisms and their offspring [4] }\end{array}$ \\
\hline Threatened release & $\begin{array}{l}\text { An imminent release that did not occur but did lead to a public health action (e.g., evacuation) that could potentially } \\
\text { affect the health of employees, emergency responders, or members of the general public }\end{array}$ \\
\hline $\begin{array}{l}\text { Transportation- related } \\
\text { incident }\end{array}$ & $\begin{array}{l}\text { Incidents occurring during the surface, air, pipeline, or water transport of hazardous substances and before a substance } \\
\text { was totally unloaded from a vehicle or vessel }\end{array}$ \\
\hline Fixed facility incident & $\begin{array}{l}\text { Incidents occurring at stationary sites, including industrial sites, schools, farms, or any other type of facility not involved } \\
\text { in the transport of hazardous substances }\end{array}$ \\
\hline Injured person(s) & $\begin{array}{l}\text { Anyone (e.g., members of the general population, employees, or emergency responders) who experiences at least one } \\
\text { documented adverse health effect within 24 hours after an incident or who dies as a consequence of an incident. Injured } \\
\text { persons may have been exposed to more than one chemical and may experience more than one injury or symptom as a } \\
\text { result of exposure }\end{array}$ \\
\hline
\end{tabular}

\section{NTSIP fosters safer chemical} alternatives:

Oregon participates on an Eco-certification Technical Advisory Committee (TAC) aimed at implementing the use of safer chemicals

In 2009, the Oregon Senate passed Bill 757, which created a priority pollutant list of chemicals contributing to surface water contamination. In an effort to reduce the use of these chemicals, the OR NTSIP participated in a TAC with various stakeholders. The TAC developed a list of over 100 safer chemical alternatives that can be used in place of the chemicals on the priority pollutant list. The TAC hopes to use the safer chemical list to convince industries to switch, reducing the effect on surface waters as well as human exposure.

\subsection{Combined State NTSIP Results for 2011}

The following sections (3.21-3.27) discuss the 2011 results in detail; specific results are categorized under appropriate subheadings characterizing response activity. State success stories and impacts are highlighted throughout the results section.

\subsection{Showcasing State Impact Through Project Highlights}

Since the inception of the NTSIP in January 2010, state cooperative agreement partners have been collecting, tracking, and submitting outreach activities and other effects to ATSDR. For 2011, a total of 30 outreach activities were completed, with a target audience of approximately 20,535 people. The highlighted stories in this document not only reveal how state NTSIP activities affect public health, but they also help to educate communities about NTSIP and strengthen the relationship among state, local, and federal governments and the communities they serve.

\subsection{Incidents}

In 2011, there were 5,691 incidents entered into the NTSIP system; of those, 3,128 (55.0\%) were eligible and 2,563 (45.0\%) were ineligible incidents under the definition of NTSIP. With the cooperative agreement stating that $80 \%$ of chemical incidents must be entered into 


\section{NTSIP Promotes Safety:}

NC NTSIP forms a Hazardous Materials Mitigation Task Force

In an effort to reduce the risk of transportation-related spills in the state, the North Carolina (NC) NTSIP formed a task force to provide guidance on the safe movement of chemicals throughout the state. Through this task force, NC NTSIP has successfully (1) provided guidance to the NC Department of Transportation on the need for a traffic signal at a busy intersection near a pipeline; (2) provided guidance to the NC LEPC on the need for road closures in the center of an ethanol transportation and loading operation; and (3) created a survey to assess and evaluate the "health" of LEPCs in the state. the NTSIP database within 48 hours, many states enter all chemical incidents into the system and later use additional information that is released about the incidents to classify their eligibility according to the NTSIP definition. The most common reasons for ineligibility were as follows: (1) there was no actual release (i.e., the "release" was threatened only) $(30.9 \%)$; (2) the incident was a petroleum release that resulted in no public health action or injury (25.5\%); or (3) the quantity released was not large enough under the NTSIP definition (8.7\%). The remainder of this section describes the characteristics of the 3,128 eligible incidents.

More incidents occurred in fixed facilities $(\mathrm{n}=2,163)$ than during transport $(n=965)$. Within these incidents, 403 fixed facility incidents resulted in 1,061 injuries, while 62 transportation-related incidents resulted in 116 injuries. Twice as many fatalities occurred in fixed facility incidents than in transportation-related incidents (Table 3).

The number of incidents reported within each state tended to correlate with the population size of the state; states with larger populations, such as New York (2010 estimated population 19 million), generally reported more incidents overall, more incidents with injured persons, and a greater number of injured persons than states with smaller populations, such as Oregon (2010 estimated population 3.8 million). All reporting states except Wisconsin recorded at least one fatality (Table 3).

Additionally, some states have access to more sources for collecting information and monitoring injuries related to NTSIP-eligible incidents; these sources include Emergency Medical Services (EMS) call logs, first responder news, and hospital discharge data. Such access allows states to collect more complete data with regard to the number and types of injuries sustained in incidents.

Initial notification about a chemical incident can occur through a variety of sources. Over $92 \%$ of incidents $(n=2,889)$ were reported through five primary notification sources, namely, emergency government/ emergency services (28.7\%), DOT/HMIS (21.0\%), media (19.5\%), environmental department or division (17.0\%), and NRC (6.1\%).

Fixed Facility

Fixed facility incidents include all incidents that occur in stationary structures (i.e., buildings) or through transport within a stationary structure (i.e., a facility rail system for moving chemicals within a chemical manufacturing plant. A chemical spill that occurs during the loading of a chemical shipment onto a truck for transport before the entire shipment is loaded is also considered a fixed facility event. The specification of the area or equipment involved in an incident is important for the understanding of fixed facility incidents. Of the 710 
total fixed facilities incidents in which either an area or equipment was the cause of the spill, over $72.1 \%(n=512)$ of the incidents involved the following three areas or types of equipment:

- 240 incidents (33.8\%) were attributable to a pipe failure.

- In 137 (19.3\%) incidents, two or more equipment pieces or areas were involved.

- 135 incidents (19.0\%) were caused by ancillary process equipment failure.

The remaining $27.9 \%$ of incidents occurred in an above-ground storage area, including a warehouse, a tank, or a storage shed $(\mathrm{n}=58,8.2 \%)$; in a process vessel $(\mathrm{n}=36,5.1 \%)$; within a transformer or capacitor $(\mathrm{n}=23,3.2 \%)$; and in a material handling area or loading dock $(\mathrm{n}=$ $20,2.8 \%)$. Other incidents occurred during transportation within the facility ( $\mathrm{n}=17,2.4 \%$ ), as a result of failure with the building heating or cooling $(n=9,1.3 \%)$, in a waste area or sewer $(n=6,0.8 \%)$, in a laboratory $(n=4,0.6 \%)$, in an incinerator $(n=3,0.4 \%)$, or in a storage area below ground $(\mathrm{n}=2,0.3 \%)$. No area or equipment piece was cited for 20 of the incidents (2.8\%).

No evacuation was ordered in 1,614 fixed facility incidents, while 549 fixed facility incidents resulted in an ordered evacuation. Table 4 shows that, of the incidents in which evacuations were ordered, 115 incidents resulted in at least one injured person, accounting for a total of 501 injured people.

\section{Transportation}

Of the 965 transportation-related incidents, the majority occurred while a shipment was en route, with the incident later discovered at a fixed facility $(31.9 \%)$; during unloading from a stationary vehicle or vessel (27.6\%); and from a moving vehicle or vessel $(24.7 \%)$ (Table 5). Although the largest number of incidents occurred while a shipment was en route and only later discovered at a fixed facility, this route of transportation did not result in the largest number of injuries or fatalities. Rather, chemical releases in 31 transportationrelated incidents from a moving vehicle or vessel resulted in the highest number of injuries $(n=64)$. This route also contributed the highest number of fatalities, with 14 fatalities reported in nine incidents. Many of these fatalities were likely a result of vehicle collisions.

When specific modes of transportation were evaluated (i.e., ground, air, rail, water, or pipeline), it was found that the largest number of transportation-related incidents occurred during ground transportation ( $\mathrm{n}=816,84.6 \%)$, a category that represents transportation via tanker truck, non-tanker truck, van, automobile, or bus. Railway modes of transportation (including containers on a flat car, tank car, or box car) also accounted for a large number of incidents $(n=89,9.2 \%)$.

\subsection{Chemicals}

The program has created lists of the common chemicals involved in NTSIP incidents, including a Top 20 chemicals list for fixed facility incidents and a Top 10 chemicals list for transportation-related incidents. Of the 2,163 incidents reported in fixed facilities, the Top 20 chemicals accounted for $58.9 \%$ of the incidents; the chemicals accounting for the largest number of incidents were natural gas, carbon monoxide, chemicals involved in the production of illicit methamphetamine, and ammonia (Table 6).

Of the 965 transportation-related incidents, the Top 10 chemicals accounted for $33.2 \%$ of all incidents. Alkaline hydroxides, including sodium hydroxide and potassium hydroxide, accounted for the most transportation-related incidents (10.9\%), followed by hydrochloric acid (5.6\%), sulfuric acid (5.0\%), and hydrogen peroxide (2.5\%) (Table 7). Some of the dangers associated with these types of chemicals are that, when released during transport, they are often associated with a variety of toxic properties (i.e., caustic, corrosive, reactive, and volatile) that have the potential to expose large numbers of people and result in numerous injuries.

The pathway by which a chemical is released is important for the development of an understanding of the type of injuries to expect as well as for the development of containment or clean-up procedures and activities. Most incidents (86.2\%) had only one release type. Chemical spills (either in liquid or solid form) and volatilization of a chemical were the two most common single release types in both fixed facility and transportation-related incidents, accounting for $48.5 \%$ and $35.3 \%$ of the total incidents reported, respectively. Volatilization occurs when a liquid or solid becomes a vapor following exposure to air. Injuries can occur if the chemical spilled readily volatilizes and exposes a large number of people quickly. Of all the various types of chemical releases resulting in injuries and fatalities, volatilization contributed the largest percentage of both injuries and fatalities; 650 incidents with injured persons occurred through volatilization, accounting for more than half $(55.2 \%)$ of the injuries. The same was true for fatalities, in which half of all deaths were attributable to the volatilization of chemicals ( $\mathrm{n}=$ 29). Twenty of these volatilization fatalities occurred in fixed facility incidents, with the rest attributable to transportation-related events (Table 8). In short, results show that future response plans should target reducing exposure of both responders and the public following a volatile chemical incident.

Because exposure to a combination of chemicals can often be more toxic and detrimental than a single chemical exposure, we analyzed the total number of chemicals involved in each incident. In most incidents 


\section{NTSIP Promotes Collaboration:}

\section{Louisiana NTSIP assists the Department of Health and Hospitals in responding to a chemical spill}

Following a spill of cumene that shut down the interstate in Jefferson Davis Parish, GIS staff helped La NTSIP staff create emergency response maps that showed the spill in relation to the surrounding daycare facilities and hospitals. Knowing the proximity of the spill to vulnerable populations allowed clean-up crews to quickly secure the spill and re-open the interstate.

\section{NTSIP Promotes Education:}

\section{Tennessee NTSIP develops an ammonia Web site}

In response to an increase in the number of ammoniarelated incidents and injuries reported through NTSIP, TN NTSIP staff recognized a need to develop information for the public on ammonia and the symptoms to look for following exposure. Staff designed an ammonia Web page that is housed on the Department of Health's Web site. A link to the ammonia Web site can be found at http://health.state.tn.us/environmental/ammonia.shtml
$(93.8 \%, \mathrm{n}=2,934)$, only one chemical was involved, while $3.5 \%$ ( $=109)$ of all incidents had two chemicals involved and $2.7 \%(\mathrm{n}=85)$ involved three or more chemicals. The pattern of exposure to a single chemical's causing the most injuries and fatalities continued; 1,122 persons (95.3\%) were injured by exposure to a single chemical and 59 (95.2\%) fatalities occurred by exposure to a single chemical.

Each year, NTSIP examines the data reported through states and identifies chemicals requiring more thorough analyses. This can be based on a variety of factors, including chemicals with a large number of incidents, chemicals with a large number of injuries, or industries with a large number of incidents. In 2011, NTSIP selected the top chemicals resulting in the largest number of injured persons/injuries. They include carbon monoxide, paints and dyes, and petroleum. The results from the additional analyses of these individual chemicals are presented in the following subsections.

\section{Carbon Monoxide}

Carbon monoxide is produced by the incomplete burning of various fuels, including charcoal, propane, and natural gas. Carbon monoxide is referred to as the "silent killer" because it is colorless and odorless and its victims often succumb before knowing they have been exposed.

Exposure to carbon monoxide was the leading cause of both injuries and fatalities reported to NTSIP. A total of 202 carbon monoxide incidents were entered into the NTSIP database in 2011; among these incidents, 256 injuries were reported (Table 9). The most common adverse health effects included dizziness or other central nervous system (CNS) symptoms (56.6\%), a combination of any two adverse health effects (19.1\%), and a combination of any three adverse health effects $(10.9 \%)$.

Exposure to carbon monoxide resulted in 18 fatalities, 16 occurring in fixed facility incidents and two in transportation-related incidents.

The NAICS code for the real estate sector (NAICS code 53) was found to have the largest number of incidents, 90 (44.6\%). NAICS code 53 applies to incidents occurring in housing structures, including apartment complexes. The utilities sector (NAICS code 22), reporting 18 incidents (8.9\%), had the second highest number of carbon monoxide incidents. There were 38 incidents that occurred in a private home and 15 with no industry. For more information on reducing exposure to carbon monoxide, please refer to the CDC carbon monoxide prevention website at http://www.cdc.gov/CO. 


\section{NTSIP Promotes Assistance: NY NTSIP assists with New York State Oil Spill Relocation Program}

Devastating weather systems in the northeast (including Hurricane Irene and Tropical Storm Lee) resulted in an increase in the number of petroleum releases in New York State. In Westchester County, a 100-unit apartment complex was evacuated following the release of fuel from a 500-gallon tank stored in the basement. After notification of the county health department by NY NTSIP, the Indoor Health Assessment Section assisted affected residents to address exposure concerns, conduct indoor air monitoring, and provide outreach.
Paints and Dyes

Paints and dyes were chosen as a chemical of interest in 2011 because of the large number of injuries $(n=61)$ related to exposure to them.

As is typical of exposure to fumes from paints and dyes, over $72 \%(\mathrm{n}=$ 44) of the 61 exposed injured persons experienced respiratory system problems, while others suffered from health effects that were not reported or were missing ( $\mathrm{n}=15,24.6 \%$ ), skin irritation ( $\mathrm{n}=1,1.3 \%)$, and non-chemical-related trauma $(n=1,1.3 \%)$ (Table 10).

When we examined paint and dye incidents by NAICS code, we found that the transportation and warehousing sector (NAICS Code 48) accounted for the greatest number. Twenty- four incidents (64.9\%) by air, rail, or water were attributed to this sector. The industry codes with the next highest number of incidents were construction (NAICS Code 23) and private homes or residences, each with 2 (5.4\%) incidents.

\section{Petroleum}

The chemical surveillance of incidents involving petroleum is relatively new, because incidents involving petroleum only began being reported in January 2010. Therefore, the program continues to perform additional analyses on annual petroleum data to understand the injuries and health effects of these incidents in order to quantify their impact. NTSIP does not include all petroleum incidents - only those that involve a public health action, an injury, or a death.

One of the difficulties in analyzing petroleum data is that so many chemicals are classified under petroleum. Table 11 shows the chemical name as well as the number of incidents attributed to each. Table 11 shows that 533 total incidents occurred that were attributed to chemicals classified as petroleum; the majority of these incidents (n $=467,87.6 \%$ ) occurred in fixed facilities. Of the over 30 chemicals that comprise the petroleum class, $64.4 \%(n=343)$ were attributed to incidents involving natural gas. Incidents involving propane were the next highest, accounting for $15.2 \%(\mathrm{n}=81)$.

Petroleum resulted in 205 total injured persons, with a variety of adverse effects reported following exposure (Table 12). Burns were reported most frequently ( $\mathrm{n}=67,32.7 \%$ ); however, only seven of the reported burns were a direct result of chemical exposure. Fiftythree were a result of thermal exposure (usually indicative of a fire or an explosion involving the chemical) and seven injured persons reported both chemical and thermal burns. Trauma was the second most reported adverse health effect, with 48 (23.4\%) injured persons reporting trauma. Most of these traumas were not chemical-related (n $=35,72.9 \%$ ); however, four were a direct result of the chemical and nine injured persons reported both chemical and non-chemical-related 
trauma. Other adverse health effects of note included dizziness or other CNS symptoms $(\mathrm{n}=31,15.1 \%)$ and respiratory problems $(\mathrm{n}=16$, 7.8\%) (Table 12).

\subsection{Factors Contributing to Incidents}

\section{Timing of Incidents}

The timing of incidents (including month of the year, day of the week, and time of the day) is prominent in the occurrence of NTSIP-eligible incidents. Although a greater number of incidents occurred in warmer months (April-September) than in colder months (October-March) for fixed facilities ( $\mathrm{n}=1,146$ for April-September vs. $\mathrm{n}=1,017$ incidents for October-March.), the difference was negligible between the two time periods examined. Differences were particularly pronounced in transportation-related incidents $(n=573$ total incidents during warmer months vs. $\mathrm{n}=392$ total incidents during cooler months). During the spring and summer months, more agricultural chemicals are being transported and used, and that fact may offer an explanation of the differences observed between months. Just over 29\% $(n=629)$ of the fixed facility events and over 30\% ( $\mathrm{n}=293)$ of transportation-related events occurred in the summer months of June, July, and August. As expected, a greater number of injuries also occurred in the summer months. Approximately 36\% ( $\mathrm{n}=394)$ of injuries from fixed facility incidents and over 46\% ( $\mathrm{n}=54)$ of injuries from transportationrelated incidents occurred during the summer months. In addition, the majority of incidents ( $\mathrm{n}=2,605,83.3 \%$ ) occurred during the weekdays of Monday through Friday, a pattern that is consistent with a standard business schedule and the occurrence of most commerce. Almost $76.7 \%$ of injuries $(n=903)$ resulted from incidents during weekdays.

We also examined the time at which the event occurred to determine whether more incidents or injuries occurred at a specific time of day. When the 24-hour day was broken down into two 12 hour time periods (from 6:00 am to 5:59 pm and from 6:00 pm to 5:59 am), it was determined that time of day had an effect on the number of incidents. Approximately 49.7\% of incidents occurred between 6:00 am and 5:59 pm $(n=1,556)$, with the remainder of events $(n=1,023$; $32.7 \%$ ) occurring in the overnight hours of 6:00 pm to 5:59 am. However, when we examined the number of injuries that occurred in each 12-hour period, we found that more injuries occurred in the overnight hours $(6: 00 \mathrm{pm}$ to $5: 59 \mathrm{am})$ than in the daylight hours (6:00 am to $5: 59 \mathrm{pm})[\mathrm{n}=518(44.0 \%)$ and $432(36.7 \%)$ injuries, respectively]. For the remaining $550(46.7 \%)$ incidents, no time was recorded; these incidents in which no time was recorded resulted in 227 (19.3\%) injuries.

\section{Weather}

Weather also contributes to the timing of incidents, and 2011 was among the most extreme years for weather events in the history of record keeping [6]. Over 14 weather-related disasters occurred in 2011 , resulting in at least $\$ 1$ billion damage each; these included the prolonged heat wave/drought in the southern plains and the Southwest, Hurricane Irene, tornadoes, and wildfires in Texas, Arizona, and New Mexico. While each of these weather incidents may not have directly affected NTSIP states, these incidents do show that extreme weather can have an impact on a variety of factors that could contribute to a chemical spill or release in a NTSIP state, including transportation pathways or timing of incidents.

All NTSIP-eligible incidents were analyzed for varying weather conditions by season-spring, summer, fall, and winter. Weather conditions were not a factor in the majority of fixed facility and transportation-related incidents $(\mathrm{n}=2,092,96.7 \%$, and $\mathrm{n}=951$, $98.5 \%$ respectively). Although weather conditions played a role in less than $3 \%$ of incidents, weather-related disasters, including hurricanes, tornados, and floods, were the most common weather-related factor contributing to NTSIP incidents ( $\mathrm{n}=24,0.8 \%$, all in fixed facilities), followed by extreme heat $(\mathrm{n}=16,0.5 \%)$, rain $(\mathrm{n}=14,0.4 \%)$, and snow, ice, sleet, or hail $(\mathrm{n}=12,0.4 \%)$. Of the total number of NTSIPeligible incidents in which weather was a contributing factor, only rain and weather disasters contributed to events in all four seasons.

\section{Primary/Secondary Contributing Factors}

Understanding contributing factors that lead to a chemical release is the key to reducing chemical spills and the injuries associated with such spills. Primary contributing factors (Table 13) are the fundamenta conditions that may have led to a hazardous release, while secondary contributing factors (if applicable) (Table 14) are any additional factors that may also have played a role in an incident. If either a primary or a secondary contributing factor was chosen, a more specific factor was entered into the database; such factors are referred to as primary and secondary supplemental factors (Tables 15 and 16). Although the specific factors are not always entered, when they are reported such factors provide more insight into the circumstances surrounding a release.

A primary factor was specified in $98.7 \%$ of all NTSIP-eligible incidents; $43.3 \%$ of incidents were the result of equipment failure, and $42.1 \%$ of incidents were caused by human error (Table 13). Equipment failure was the leading factor in fixed facility incidents (51.0\%), as opposed to human error $(69.0 \%)$ in transportation incidents. 
The primary contributing factors of equipment failure and human error also resulted in the majority of injured persons $(n=448,38.1 \%$ and $\mathrm{n}=421,35.8 \%$, respectively). In fixed facility events for which a primary contributing factor was reported, equipment failure resulted in the largest number of events with injuries ( $n=423,39.9 \%)$, while human error was the cause of the largest number of transportationrelated events with injuries $(n=76,65.5 \%)$. Other factors contributing to injuries were in the categories of 'intentional', 'other', 'bad weather conditions/natural disasters,' and 'illegal act' (Table 13).

The more specific primary supplemental factors contributing to a chemical release were varied, with the most common factor being 'other' $(\mathrm{n}=724,23.2 \%)$. This category refers to any additional factor that may have contributed to the spill, but were not captured in the provided list. This factor was followed by improper filling, loading, or packing ( $\mathrm{n}=$ $553,17.7 \%)$, illicit drug production-related incidents $(\mathrm{n}=200,6.4 \%)$, or a system/process upset $(\mathrm{n}=192,6.1 \%)$. It is important to note that a primary supplemental factor was not entered in over $23.8 \%(n=746)$ of the total incidents. Additional details about primary supplemental factors can be found in Table 15 .

The majority of incidents did not have a secondary contributing factor $(\mathrm{n}=2,284,73.0 \%)$. For those incidents in which a secondary contributing factor was reported, equipment failure was the most common reason ( $\mathrm{n}=420,13.4 \%)$, while when a secondary supplemental factor was reported, the largest number of incidents noted other $(101,3.2 \%)$, fire $(\mathrm{n}=53,1.7 \%)$ and explosion $(\mathrm{n}=51,1.6 \%)$ as supplemental factors in the incident. Additional details regarding secondary contributing and supplemental factors can be found in Tables 14 and 16 .

\subsection{Injury Characterization}

Of the 3,128 NTSIP-eligible incidents, 466 (14.9\%) resulted in a total of 1,177 injured persons; this means in over $85 \%$ of NTSIP-eligible incidents $(n=2,663)$, no injuries were reported. Thirty-five fixedfacility and 3 transportation incidents had 6 or more people injured (Table 17). When injuries were characterized according to severity or disposition, over $70 \%$ of all injuries resulted in treatment at a hospital without admittance $(n=682)$ or in treatment on the scene by first aid $(n=153)$. Seventeen percent of injuries required the injured person to be admitted to a hospital for treatment $(n=200)$, and 55 persons died either on the scene or on arrival at the hospital, while 7 persons died after arrival the hospital. Other outcomes experienced by individuals following exposure included injuries experienced within 24 hours of the incident and reported by an official (e.g., fire department staff or EMT; $n=61,5.2 \%$ ), injuries tended to by a private physician within 24 hours of the incident $(n=6,0.5 \%)$, and injuries requiring observation at a hospital with no treatment $(n=4,0.3 \%)$ (Table 18).

\section{Category, Age, and Gender of Injured People}

For all incidents with injuries, injured people were categorized into a victim category; the public, consisting of both the general public and students at school, accounted for just over half of all injuries (54.6\%). Other victim categories included employees $(31.0 \%)$ and responders, including hospital personnel (14.2\%). Responders and hospital personnel were further separated into types, with career firefighters being the most frequent (8.5\%) (Table 19). Of the 760 injured persons with reported gender, over $72.1 \%$ were male; however, the breakdown was dependent on the victim category. More male than female employees were injured (Table 20). The inequality may be explained by the general existence of more males than females who are employed in factory environments, where workers can be readily exposed to chemical releases. A similar pattern is also observed with respect to responders and hospital personnel: over 20 times' more male responders were injured than female responders (Table 20). First responders in emergency situations are generally predominantly male. This pattern was also observed in the public category, where injuries suffered by males once again outnumbered those of females (Table 20); 237 males in the public sector were injured, compared with 158 females. Of the 1,045 people injured for whom data by age existed, $13.5 \%$ were children (under 18 years of age).

\section{Adverse Health Effects of Injured People}

Depending on the types of chemicals that result in injuries, a variety of adverse health effects can be observed, including trauma, respiratory irritation, eye irritation, burns, headache, and others. Of 1,177 total injured persons, the majority of injured people $(n=869,73.8 \%)$ reported one adverse health effect. The most commonly reported adverse health effects were respiratory system problems (21.8\%), dizziness or other CNS problems (17.7\%), burns (13.1\%), and trauma (11.5\%). Non-chemical-related traumas and thermal burns were probably related to a fire, an explosion, or a vehicle accident, not direct exposure to a chemical. Over 22.8\% of injured people reported more than one adverse health effect (Table 21).

\section{Personal Protective Equipment (PPE)}

Because the level of personal protective equipment (PPE) worn by a first responder should reduce or mitigate adverse effects from chemical exposure, it is imperative to document the type of protection that injured emergency responders were wearing when they were injured. Emergency responders and employees were the only victim categories to answer the PPE question; the public (including both students and the general public) would generally not have access to PPE beyond such basic equipment as gloves or masks [7]. Of the 1,015 total individuals injured while not wearing PPE, 344 (33.9\%) of them were responders 


\section{NTSIP fosters Preparation: Utah develops social vulnerability maps}

UT NTSIP staff developed a social vulnerability map for Salt Lake County. A standard protocol of eight variables, including (1) number of people less than 18 years old, (2) number of people greater than 64 years old, (3) number of females, (4) number of non-white ethnicities, (5) number of housing units, (6) total population, (7) number of mobile homes, and (8) mean home value were used to measure vulnerabilities in the population living in the county. By use of 2000 U.S. Census data collected at the census block group level, Utah compared one block group to another group within the county to establish risk comparisons and populate the vulnerability map. These maps will show NTSIP areas in the county at a higher susceptibility for the effects of chemical exposure. or employees, showing that at least one third of injuries could have potentially been prevented with proper access to PPE.

The majority of injuries to response personnel occurred to firefighters who were wearing firefighter turnout gear but were not equipped with respiratory protection. Of these injured persons, 60 were classified as career firefighters, 12 as volunteer firefighters, and 1 as an unspecified firefighter. In addition, a total of 56 injured persons were wearing firefighter turn-out gear with respiratory protection: career firefighters $(n=37)$, volunteer firefighters $(n=6)$, and unspecified firefighters $(n=13)$.

Decontamination Status

Decontamination is the reduction or removal of chemical agents. Chemical decontamination is generally accomplished through detoxification or neutralization. Because the decontamination process can be involved, costing both time and money, it is important to know the number of people decontaminated at a site, what chemical exposures resulted in decontamination, and the place where decontamination occurs (i.e., at the scene of the incident, at a medical facility, or both). This information helps first responders as well as hospital staff better prepare for chemical incidents. The decontamination status of all injured people shows that the majority were not decontaminated $(\mathrm{n}=$ $945,80.3 \%)$.

Of the total number of injured people, $7.7 \%(n=91$ injured people) were decontaminated at a medical facility and 8.0\% $(n=94$ injured people) were decontaminated at the scene of the incident. Additionally, 38 injured people (3.2\%) were decontaminated at both the scene of the incident as well as at a medical facility.

Because decontamination can be necessary for individuals not suffering an injury (i.e., first responders at the scene of a chemical spill or release), we also examined decontamination among non-injured people. Of people not suffering an injury and requiring decontamination, the majority were decontaminated at the scene of the incident $(\mathrm{n}=35$, $1.3 \%)$. An additional 5 non-injured people (0.2\%), however, were decontaminated at a medical facility. The relatively small number of non-injured people who required decontamination reinforces the fact that the majority of the first responders and clean-up personnel were wearing PPE adequate for both the response situation and the chemical released.

\subsection{Response and Evacuation}

Emergency Response

The majority ( $\mathrm{n}=2,258,72.2 \%)$ of NTSIP-eligible incidents did not require any actions to protect public health. Of those incidents requiring public health actions, more were taken in fixed facility incidents than in transportation-related incidents $(\mathrm{n}=817,37.8 \%$ of fixed facility incidents and $n=53,5.5 \%$ of transportation-related 
incidents, respectively). In fixed facility incidents, the public health action undertaken most frequently was environmental sampling (n $=558$ incidents), followed by another activity not listed ( $\mathrm{n}=134$ incidents) and incidents in which two or more activities were taken to protect public health ( $\mathrm{n}=106$ incidents). Similarly, environmental sampling was the most prevalent public health action undertaken in transportation-related incidents $(\mathrm{n}=37)$. This was followed by another activity not listed ( $\mathrm{n}=9$ incidents), and incidents in which two or more activities were taken to protect public health ( $\mathrm{n}=2$ incidents).

Notable health actions included five incidents that required the addition of a health investigation; these investigations are generally necessary following the release of a chemical that exposes a large number of people and, depending on the severity of the injuries, can result in an epidemiological study, medical monitoring of the exposed person(s) over time, or an exposure assessment. In four incidents, the chemical release affected a drinking water source, causing communities to switch to an alternative water source. Additionally, in two incidents, the chemical spill affected groundwater wells, causing the need for a well survey to be conducted.

An examination of the type of responders aiding in NTSIP-eligible incidents shows that $40.6 \%$ of incidents were responded to by a company response team: $33.0 \%$ of fixed facilities incidents and $57.7 \%$ of transportation-related incidents (Table 22). More than a third of the incidents ( $\mathrm{n}=1,247,39.9 \%)$ required multiple types of responders. Fixed-facility incidents were more likely to require multiple types of responders (46.7\%) than transportation incidents (24.3\%). Only 122 incidents (3.9\%) did not require a response (Table 22).

\section{Evacuation and in-place sheltering}

Evacuation occurred when the potential for an exposure required people to leave the area for the protection of their health. Alternatively, in some situations, people in the area were alerted to shelter-in-place or to remain inside with exterior doors and windows closed and the heating, ventilation, and air conditioning systems turned off until the threat had been remediated. In 2011, there were 582 incidents (18.6\%) requiring an ordered evacuation, while an additional 72 incidents $(2.3 \%)$ resulted in a shelter-in-place order.

In incidents requiring an ordered evacuation, the number of people evacuated generally depended on where the incident occurred, the time of day, and the land use areas surrounding the incident. The majority of incidents that required an ordered evacuation ( $\mathrm{n}=387$ or $66.4 \%$ ) required the evacuation of 50 or fewer people. A larger number of fixed facility incidents required evacuations than did transportation-related incidents $(\mathrm{n}=549$ and $\mathrm{n}=33$, respectively). When a release occurs in a facility, it generally occurs indoors, with the potential to expose workers who are employed by the facility. Such a release necessitates an evacuation. On the other hand, in transportation-related incidents, a release generally occurs outdoors. Although an outdoor release can generally allow a contaminant to travel further, potentially exposing a larger number of people, it can also allow the contaminant to dilute into air or water, thus reducing its toxic effects.

Approximately four in 10 incidents requiring an ordered evacuation $(\mathrm{n}=247,42.5 \%)$ affected a single general land use. The most common single general land use in incidents included (in decreasing order by total number of incidents): residential ( $\mathrm{n}=132$ incidents), commercial ( $\mathrm{n}=66$ incidents), industrial ( $\mathrm{n}=42$ incidents), undeveloped $(\mathrm{n}=4$ incidents), agricultural ( $\mathrm{n}=2$ incidents), and recreational areas $(\mathrm{n}=1$ incident). When we evaluated mixed land use (consisting of any two different land uses), we found that approximately $49 \%$ of incidents ( $\mathrm{n}=285$ ) occurred in a combination of both commercial and residential areas.

\section{Vulnerable populations}

The proximity of a chemical release to vulnerable populations is of concern because vulnerable populations may need additional time or assistance during an evacuation and may be more vulnerable to lower levels of contaminants. Therefore, it is critical that these populations be identified prior to the occurrence of a chemical incident to ensure that they receive assistance during an evacuation or a sheltering-inplace process. NTSIP regards vulnerable populations as those living in places in which people sensitive to chemical exposures may reside, including residences, schools, hospitals, nursing homes, licensed day care facilities, or recreational areas (e.g., parks). While almost 99\% of all NTSIP incidents requiring an ordered evacuation $(n=575)$ had at least one type of vulnerable population within a quarter-mile of the release, many incidents had numerous populations identified. Of the 582 incidents requiring an evacuation, $490(84.2 \%)$ had two or more different vulnerable population facilities within a quarter-mile.

\subsection{Industry Codes}

For all qualifying NTSIP-eligible incidents, an Industry Code based on the North American Industry Classification System (NAICS) was entered into the database. The NAICS is the standard used by federal statistical agencies in classifying business establishments for the purpose of collecting, analyzing, and publishing statistical data related to the U.S. business economy.

In 2011, the largest number of NTSIP-eligible incidents $(\mathrm{n}=902$ or 28.8\%) were attributed to the transportation and warehousing sector (NAICS codes 48 and 49) (Table 23). This sector includes transportation by air, rail, water, truck, transit, as well as ground passenger, pipeline, scenic and sightseeing, transportation support activities, postal services, 


\section{NTSIP Promotes Innovation: WI NTSIP creates data-usage for identifying chemical vulnerabilities}

Wisconsin (WI) NTSIP data were used in conjunction with the ESRI-Business Analyst (BA) program to identify areas in the state vulnerable to chemical exposure. Areas were selected within the state to pilot using chemical storage and census data as indicators. WI NTSIP staff piloted the program with the City of Oshkosh Health Department (COHD), demonstrating the proximity between a chemical storage company and sensitive populations. Since the successful pilot test, WI NTSIP has secured a similar partnership with the Kenosha County Public Health Department. and couriers. Second in the number of incidents was the manufacturing sector (NAICS codes 31, 32, and 33) ( $\mathrm{n}=570$ or 18.2\%). The largest number of incidents within this code grouping was in NAICS code 32 ( $\mathrm{n}=454$ or $14.5 \%)$. Code 32 is associated with the manufacturing of wood, paper, printing, petroleum and coal, chemical, plastic and rubber, and non-metallic minerals.

Although the transportation and warehousing sector had the largest number of incidents, private residences accounted for the largest number of injuries. In 484 incidents occurring in private residences, there were 327 injuries. This number was much higher than the combined injuries in the two sectors with the next highest injuries, real estate and rental leasing (NAICS code 53; 119 injuries) and educational services (NAICS code 61), which accounted for 76 injuries in 77 incidents. The fact that the largest number of injuries occurred in private residences highlights this sector as a sub-population that may require additional information targeted at reducing common injuries related to exposures (Table 23).

While there was a large percentage of incidents attributed to the manufacturing sector (18.2\%), there were fewer injuries in that sector (6.3\%) (Table 23).

\subsection{National Database}

NTSIP continues to use data collected and reported from the cooperative agreement partner states, coupled with supplemental data from governmental reporting agencies (i.e., DOT and NRC), to create national estimates of chemical incidents on an annual basis. The national estimates are important for monitoring trends and publishing information regarding relevant chemical exposure prevention. For a detailed description of the national database, its core functions, and key partnerships, refer to Table 1 .

Fixed facility estimates are calculated by use of the NRC IRIS data, while transportation-related incidents are estimated by use of the DOT HMIS data. Modeled fixed facility and transportation data are calculated through use of a matching ratio derived from the comparison of statereported NTSIP incidents and incidents reported from the appropriate data source (NRC for fixed facility and DOT for transportation) for current NTSIP states. This ratio is then applied to NRC or DOT records for non-participating NTSIP states for the derivation of an estimate of NTSIP-eligible chemical incidents for a particular year. The NTSIP national database can be accessed via the NTSIP Web site.

Currently, NTSIP has data-sharing agreements with the EPA Risk Management Plan (RMP) and the American Association of Poison Centers to try to match records for even more precise national incident estimates. 
Table 24. NTSIP-eligible incident estimates for fixed facility and transportation incidents for the 43 states not currently reporting to NTSIP and actual counts for the seven bolded, NTSIP funded states.

\begin{tabular}{|c|c|c|c|}
\hline & & 2011 Estimatec & orted Incidents1' \\
\hline State & State Abbreviation & Fixed Facility & Transportation \\
\hline Alabama & $\mathrm{AL}$ & 212 & 65 \\
\hline Alaska & AK & 69 & 47 \\
\hline Arizona & $\mathrm{AZ}$ & 53 & 113 \\
\hline Arkansas & AR & 165 & 56 \\
\hline California & $C A$ & 858 & 524 \\
\hline Colorado & $\mathrm{CO}$ & 79 & 143 \\
\hline Connecticut & CT & 147 & 58 \\
\hline Delaware & $\mathrm{DE}$ & 78 & 5 \\
\hline Florida & $\mathrm{FL}$ & 459 & 228 \\
\hline Georgia & GA & 210 & 160 \\
\hline Hawaii & $\mathrm{HI}$ & 53 & 4 \\
\hline Idaho & $\overline{I D}$ & 34 & 19 \\
\hline Illinois & IL & 292 & 428 \\
\hline Indiana & IN & 133 & 159 \\
\hline lowa & IA & 94 & 48 \\
\hline Kansas & KS & 147 & 112 \\
\hline Kentucky & $\mathrm{KY}$ & 196 & 141 \\
\hline Louisiana & LA & 528 & 267 \\
\hline Maine & $\mathrm{ME}$ & 60 & 12 \\
\hline Maryland & MD & 152 & 114 \\
\hline Massachusetts & MA & 165 & 89 \\
\hline Michigan & $\mathrm{Ml}$ & 195 & 110 \\
\hline Minnesota & $\mathrm{MN}$ & 92 & 80 \\
\hline Mississippi & MS & 127 & 40 \\
\hline Missouri & M0 & 117 & 107 \\
\hline Montana & MT & 23 & 21 \\
\hline Nebraska & $\mathrm{NE}$ & 71 & 16 \\
\hline Nevada & NV & 17 & 41 \\
\hline New Hampshire & $\mathrm{NH}$ & 33 & 12 \\
\hline New Jersey & NJ & 381 & 132 \\
\hline New Mexico & NM & 38 & 21 \\
\hline New York & NY & 1,022 & 186 \\
\hline North Carolina & NC & 143 & 108 \\
\hline North Dakota & ND & 48 & 9 \\
\hline Ohio & $\mathrm{OH}$ & 340 & 305 \\
\hline Oklahoma & OK & 140 & 64 \\
\hline Oregon & $\mathbf{O R}$ & 85 & 75 \\
\hline Pennsylvania & PA & 437 & 273 \\
\hline Rhode Island & $\mathrm{Rl}$ & 23 & 15 \\
\hline South Carolina & SC & 105 & 59 \\
\hline South Dakota & SD & 11 & 8 \\
\hline Tennessee & TN & 174 & 151 \\
\hline Texas & TX & 1,687 & 536 \\
\hline Utah & UT & 101 & 50 \\
\hline Vermont & VT & 31 & 4 \\
\hline Virginia & VA & 287 & 74 \\
\hline Washington & WA & 293 & 76 \\
\hline West Virginia & WV & 104 & 18 \\
\hline Wisconsin & WI & 110 & 128 \\
\hline Wyoming & WY & 53 & 5 \\
\hline & Total ${ }^{2}$ & 10,497 & 5,474 \\
\hline
\end{tabular}

${ }^{1}$ The National Database can be found on the NTSIP Web site at https://hip.phmsa. dot.gov/analyticsSOAP/saw.dll?Dashboard\&NQUser=ATSDRPortalAccess\& NQPassword=ATSDRP0rt@lAcc3ss\&PortalPath=/shared/ATSDR/_portal/ ATSDR\%20Portal. Bolded numbers represent actual events in NTSIP reporting states while numbers not bolded represent incident estimates in non-reporting states.

${ }^{2}$ The total number of incidents for both fixed facility and transportation-related events may not add up to the numbers reported in the HIP, since the HIP also includes U.S. territory estimates (i.e., American Samoa) in its portal. As the national database estimates for each state are collected at a specific point in time, it is possible that the estimates may change over time. This is a result of the ratios applied to each non-reporting state to obtain the estimated number of incidents.
Annual maps are included in the national database for both fixed facility and transportation-related incidents. In the portal, a user can view a cumulative map that represents data from all modeled years, or users can query by a specific year of interest.

Currently, NTSIP has modeled estimates for national chemical incidents dating back to 2000. Table 24 shows the 2011 for the seven NTSIP reporting states as well as the estimates for the remaining 43 states that currently do not report to NTSIP. These estimates are based on the reported incidents of the seven funded state programs participating in the cooperative agreement program and the additional national databases (NRC and DOT) that are used as comparison data sources.

Overall, 15,971 chemical incidents were estimated to have occurred in 2011; 10,497 occurred in fixed facilities, while transportation-related incidents were estimated at 5,474. When 2011 estimations were compared to 2010 estimations, we calculated 699 more incidents for 2011, resulting in an increase of 4.2\%. Comparing fixed facility and transportation estimates between 2010 and 2011 shows that 10.8\% more fixed facility events were estimated in 2011 than in 2010; there was, however, an $8.5 \%$ decrease in transportation-related incidents.

When we separated incidents by state, we found that $72 \%$ of states saw increases in fixed facility events between 2010 and 2011, a much higher increase than in transportation incidents, where only $12 \%$ of states saw increases. The largest increases were observed in states with greater areas; for example, New York saw a 36.9\% increase in fixed facility events, and Texas reported a $10.6 \%$ increase in transportationrelated incidents.

NTSIP continues to collect chemical surveillance data from current reporting states, and the program uses this data, coupled with supplemental data accessed from additional national surveillance systems, to estimate chemical incidents on a national scale. As additional data sources are determined to complement the state-reported data and as the methodology is further refined, more precise estimates of national chemical incidents and injuries can be derived. 


\subsection{Incident Investigation (ACE)}

When large-scale chemical incidents occur, state and local governments often need assistance to respond to and collect pertinent information about spills. In these instances, a state can request the assistance of the Assessment of Chemical Exposures (ACE) team, members of which will assist with the characterization of exposure data as well as the gathering of information about acute health effects that may result from exposure.

A state epidemiologist can request the assistance of the ACE team through the Epi-Aid mechanism if a large number (approximately 30 or more people) are exposed to a toxic substance at levels that could produce acute health effects; however, the team may investigate smaller releases as well, especially if the expected health effects are severe. The ACE team, which can be equipped with individuals from diverse backgrounds, including epidemiology, medicine, statistics, veterinary medicine, industrial hygiene, toxicology, and data management, is rapidly deployed to assist with an investigation.

Since the inception of the program, the ACE team has responded to a number of large-scale chemical exposure incidents across the country. In 2011, an ACE investigation was performed in conjunction with NIOSH following a chlorine release at an Arkansas poultry processing facility.

\subsection{Chlorine Gas Release at a Chicken Processing Plant in Arkansas: An ACE Investigation Conducted with $\mathrm{NIOSH}$}

The ACE team was deployed to investigate an incident at an Arkansas chicken processing plant in June 2011. The incident involved a chlorine gas release from an accidental mixing of incompatible chemicals. Of the 600 workers inside the plant at the time of the release, 170 were transported to five hospitals in the area for medical evaluation. The ACE team conducted key informant interviews with local responders and also surveyed the five hospitals to determine each hospital's preparedness to respond to the event. The team abstracted medical charts from all patients from the incident in order to develop a better understanding of the health effects these patients experienced.

Additionally, the ACE team collaborated with NIOSH responders who were conducting a Health Hazard Evaluation (HHE) at the plant. Following the site visit, NIOSH personnel provided a detailed report of their findings and outlined recommendations to prevent future occurrences. A report of the NIOSH investigation was also published in CDC's Morbidity and Mortality Weekly Report [6].
Five months after the joint investigation, NIOSH personnel returned to re-survey workers for longer-term health effects, and members of the ACE team met with hospitals and responders to discuss the team's findings and recommendations.

During the ACE investigation, it was discovered that due to existing notification criteria, the Arkansas Department of Health (ADH) was not notified of the incident until several hours after the release and therefore was unable to provide assistance. Many of the exposed workers were not fluent in English and there were difficulties with communication both at the scene and at the hospitals. $\mathrm{ADH}$ had personnel who could have helped with communication in the two needed languages and who could have assisted hospitals by creating discharge instructions in the patients' native languages had they been involved during the response.

To ensure the that $\mathrm{ADH}$ is notified of all chemical, biological, nuclear, radiological, and explosive incidents in the future, $\mathrm{ADH}$ worked with the Arkansas Department of Emergency Management to modify the notification criteria. The new protocol was tested in February 2012, when two releases of ammonia occurred at two different facilities in the same city on the same day. As a result of the new criteria for notification, $\mathrm{ADH}$ was quickly notified of the releases and was able to provide information and support to the hospital where patients were treated.

Additionally there were issues identified with communication from the scene of the incident to the hospitals. As a result, the hospitals are continuing to strengthen relationships though coordinated exercises with the local Office of Emergency Management to ensure good communication and coordination in response to incidents in the future.

Another finding of the investigation was that hospitals who received information on patient care from $\mathrm{ADH}$ or the Arkansas Poison and Drug Information Center were aware that there could be a delay in onset of symptoms. These hospitals observed patients for a longer time period than hospitals not receiving this information. This finding highlights that hospital communication with the health department and poison center can be important in providing optimal patient care. ACE investigations collect data from incidents with different chemicals released, varying numbers of injured persons, and diverse geographical locations. Data from these incidents are summarized to obtain a more comprehensive picture of acute chemical exposure. Lessons learned from each incident are published to inform public health practitioners and first responders not only of the health hazards associated with acute chemical exposures, but also of how to apply these lessons learned to better preparation for future releases. 


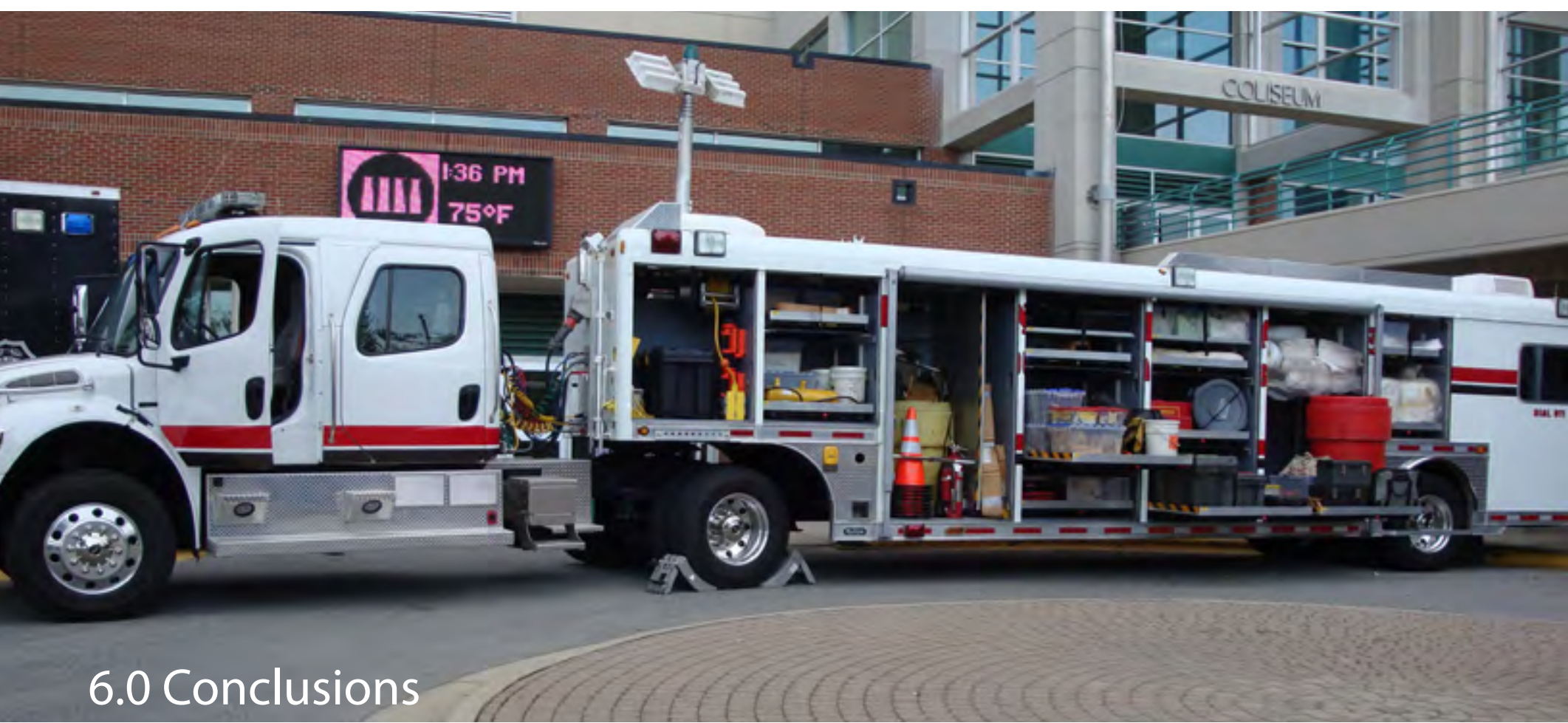

This report highlights the important findings from the combined 2011 NTSIP state surveillance data analysis. These results help reporting states as well as ATSDR to evaluate the programs and determine priorities for the next year of data analysis. With this knowledge, NTSIP state coordinators and ATSDR staff are more equipped to create targeted intervention strategies aimed at fulfilling the program's mission and vision.

Analysis of the 2011 data shows that the program is collecting information useful for understanding acute hazardous chemical exposures. Both NTSIP federal and state staff are continuously monitoring the data to determine specific trends in chemical incidents to develop outreach and prevention activities targeted at reducing injuries and deaths associated with chemical events.

The impact stories summarized in the annual report show both the depth and variety of the program's activities. As each state program creates activities that focus on issues pertinent to their state, they are charged with addressing and finding innovative solutions to proactively assist emergency management and responders with the necessary information to reduce the effect of a chemical spill. Additionally, at ATSDR, the ACE team has been a resource for states to use when these types of spills occur, for this team aids in the collection and documentation of information relevant to the event. Data collected from these types of events are then used to develop publications and presentations in which lessons learned can be used in the proactive planning for future incidents.

As the only comprehensive surveillance system for acute chemical exposures, NTSIP continues to fill an important gap in chemical incident reporting. The data collected through individual state reporting, coupled with the information gained through both the national database and ACE programs, ensure that a complete national chemical spill story is told. As this program continues its chemical surveillance activities, the data collected will become more powerful and useful in the proactive prevention of chemical releases. 


\subsection{References}

[1] American Chemical Council. (2013). "U.S. Chemical Production Continues Growth Trend; Production Up 1.2\% Over Year Ago". American Chemistry Council News Release. http://www.americanchemistry.com/Media/PressReleasesTranscripts/ACC-news-releases/US-ChemicalProduction-Continues-Growth-Trend-Production-Up-12-Percent-Over-Year-Ago.html. Accessed 05/03/2013.

[2] Agency for Toxic Substances and Disease Registry (ATSDR) (2013). National Toxic Substance Incidents Program (NTSIP) Annual Report, 2010. U.S. Department of Health and Human Services, Environmental Health Surveillance Branch, Division of Toxicology and Human Health Sciences. Atlanta, Georgia.

[3] Squire, Richard H. (2001). “Zero Period Process-A Description of a Process to Zero Injuries”. Process Safety Progress 20(1): 17-28.

[4] Mannan, M. Sam, PhD. (2012). “The Need for a National Hazardous Substances Incident Surveillance System- Public Health and Chemical Accident Prevention". Presentation at CDC on February 11, 2012

[5] Agency for Toxic Substances and Disease Registry (ATSDR). (2011). National Toxic Substance Incidents Program (NTSIP) Protocol. Environmental Health Surveillance Branch. Atlanta, Georgia.

[6] National Oceanic and Atmospheric Administration (NOAA). Extreme Weather 2011: A Year for the Record Books. https://noaa.gov/ extreme2011/. Accessed 03/29/2013.

[7] Environmental Protection Agency (EPA). (2011). Personal Protective Equipment. Emergency Hazardous Substances. Available at: http:// www.epa.gov/osweroe1/content/hazsubs/equip.htm. Accessed 03/01/2013.

[8] Centers for Disease Control and Prevention (CDC). Chlorine gas release associated with employee language barrier-Arkansas, 2011. Morbidity and Mortality Weekly Report (MMWR) 2012; 61(48): 981-985. 


\section{Appendix A: 2011 NTSIP Publications}

Centers for Disease Control and Prevention (CDC). (2011). Chlorine gas exposure at a metal recycling facility—California, 2010. Morbidity and Mortality Weekly Report (MMWR) 2011; 60(28): 951-954.

Centers for Disease Control and Prevention (CDC). (2011). Chemical suicides in automobiles—six states, 2006-2010. Morbidity and Mortality Weekly Report (MMWR) 2011; 60(35): 1189-1192.

Duncan, MA, D Drociuk, A Belflower-Thomas, D Van Sickle, JJ Gibson, C Youngblood and WR Daley. (2011). Follow-up assessment of health consequences after a chlorine release from a train derailment—Graniteville, SC, 2005. Journal of Medical Toxicology 7(1): 85-91. March 2011.

Melnikova, N, WL Welles, RE Wilburn, N Rice, J Wu and M Stanbury. (2011). Hazards of illicit methamphetamine production and efforts at reduction: data from the Hazardous Substances Emergency Events Surveillance System. Public Health Reports 126(Suppl 1): 116-123.

Ruckart, PZ and MF Orr. (2011). Case Studies and Lessons Learned in Chemical Emergencies Related to Hurricanes. In: Lupo, AR (Ed.), Recent Hurricane Research (Climate, Dynamics, and Societal Impacts), pp. 483-500. Rijeka, Croatia: InTech.

Saw, L, J Shumway and P Ruckart. (2011). Surveillance data on pesticide and agricultural chemical releases and associated public health consequences in selected US states, 2003-2007. Journal of Medical Toxicology 7(2): 164-171. June 2011. 


\section{Appendix B: Supporting Data from NTSIP 2011 Annual Report}

Table 3. Number of NTSIP-eligible incidents, incidents with injured persons/fatalities, and total number of injured persons/fatalities by type of incidents and reporting states, NTSIP 2011.

\begin{tabular}{|c|c|c|c|c|c|c|c|c|c|}
\hline \multirow[b]{3}{*}{ State } & \multicolumn{9}{|c|}{ NTSIP-eligible Incidents-Injuries ${ }^{a}$} \\
\hline & \multicolumn{3}{|c|}{ Fixed Facility } & \multicolumn{3}{|c|}{ Transportation } & \multicolumn{3}{|c|}{ Total } \\
\hline & $\begin{array}{c}\text { \# of } \\
\text { incidents }\end{array}$ & $\begin{array}{c}\text { \# of } \\
\text { incidents } \\
\text { with } \\
\text { injured } \\
\text { people }\end{array}$ & $\begin{array}{c}\text { Total \# } \\
\text { of } \\
\text { injured } \\
\text { people }\end{array}$ & $\begin{array}{c}\text { \# of } \\
\text { incidents }\end{array}$ & $\begin{array}{c}\text { \# of } \\
\text { incidents } \\
\text { with } \\
\text { injured } \\
\text { people }\end{array}$ & $\begin{array}{c}\text { Total \# } \\
\text { of } \\
\text { injured } \\
\text { people }\end{array}$ & $\begin{array}{c}\text { \# of } \\
\text { incidents }\end{array}$ & $\begin{array}{c}\# \text { of } \\
\text { incidents } \\
\text { with } \\
\text { injured } \\
\text { people }\end{array}$ & $\begin{array}{c}\text { Total \# } \\
\text { of } \\
\text { injured } \\
\text { people }\end{array}$ \\
\hline Louisiana & 528 & 34 & 50 & 267 & 13 & 21 & 795 & 47 & 71 \\
\hline New York & 1,022 & 201 & 664 & 186 & 23 & 59 & 1,208 & 224 & 723 \\
\hline $\begin{array}{c}\text { North } \\
\text { Carolina }\end{array}$ & 143 & 25 & 50 & 108 & 9 & 13 & 251 & 34 & 63 \\
\hline Oregon & 85 & 10 & 28 & 75 & 2 & 2 & 160 & 12 & 30 \\
\hline Tennessee & 174 & 39 & 96 & 151 & 11 & 15 & 325 & 50 & 111 \\
\hline Utah & 101 & 81 & 118 & 50 & 1 & 1 & 151 & 82 & 119 \\
\hline Wisconsin & 110 & 13 & 55 & 128 & 3 & 5 & 238 & 16 & 60 \\
\hline Total & 2,163 & 403 & 1,061 & 965 & 62 & 116 & 3,128 & 465 & 1,177 \\
\hline \multirow[b]{3}{*}{ State } & \multicolumn{9}{|c|}{ NTSIP-eligible Incidents-Fatalities ${ }^{\mathrm{a}}$} \\
\hline & \multicolumn{3}{|c|}{ Fixed Facility } & \multicolumn{3}{|c|}{ Transportation } & \multicolumn{3}{|c|}{ Total } \\
\hline & $\begin{array}{c}\text { \# of } \\
\text { incidents }\end{array}$ & $\begin{array}{c}\text { \# of } \\
\text { incidents } \\
\text { with } \\
\text { fatalities }\end{array}$ & $\begin{array}{c}\text { Total \# } \\
\text { of } \\
\text { fatalities }\end{array}$ & $\begin{array}{c}\text { \# of } \\
\text { incidents }\end{array}$ & $\begin{array}{c}\text { \# of } \\
\text { incidents } \\
\text { with } \\
\text { fatalities }\end{array}$ & $\begin{array}{c}\text { Total \# } \\
\text { of } \\
\text { fatalities }\end{array}$ & $\begin{array}{c}\text { \# of } \\
\text { incidents }\end{array}$ & $\begin{array}{c}\text { \# of } \\
\text { incidents } \\
\text { with } \\
\text { fatalities }\end{array}$ & $\begin{array}{c}\text { Total \# } \\
\text { of } \\
\text { fatalities }\end{array}$ \\
\hline Louisiana & 528 & 3 & 3 & 267 & 2 & 2 & 795 & 5 & 5 \\
\hline New York & 1,022 & 16 & 22 & 186 & 7 & 11 & 1,208 & 23 & 33 \\
\hline $\begin{array}{c}\text { North } \\
\text { Carolina }\end{array}$ & 143 & 2 & 2 & 108 & 4 & 4 & 251 & 6 & 6 \\
\hline Oregon & 85 & 0 & 0 & 75 & 1 & 1 & 160 & 1 & 1 \\
\hline Tennessee & 174 & 7 & 12 & 151 & 3 & 4 & 325 & 10 & 16 \\
\hline Utah & 101 & 1 & 1 & 50 & 0 & 0 & 151 & 1 & 1 \\
\hline Wisconsin & 110 & 0 & 0 & 128 & 0 & 0 & 238 & 0 & 0 \\
\hline Total & 2,163 & 29 & 40 & 965 & 17 & 22 & 3,128 & 46 & 62 \\
\hline
\end{tabular}

${ }^{\mathrm{a}}$ Injuries and fatalities were analyzed independently; therefore, the number of injuries represents the number of people who sustained injury as a result of a chemical incident, while fatalities represent the number of people who died as a result of their injuries. 
Table 4. Number of fixed facility incidents, fixed facility incidents with injured people, and total number of injured people by number of employees at a fixed facility by evacuation order status, NTSIP 2011.

\begin{tabular}{|l|c|c|c|}
\hline \multirow{2}{*}{$\begin{array}{l}\text { Number of employees at fixed } \\
\text { facility }\end{array}$} & $\begin{array}{c}\text { N of Fixed Facility } \\
\text { Incidents }\end{array}$ & $\begin{array}{c}\text { \# of Fixed Facility } \\
\text { Incidents } \\
\text { with Injured People }\end{array}$ & $\begin{array}{c}\text { Total \# } \\
\text { of Injured People }\end{array}$ \\
\hline & \multicolumn{3}{|c|}{ Official Evacuation Ordered } \\
\hline 0 & 47 & 17 & 36 \\
\hline $1-5$ & 31 & 12 & 54 \\
\hline $6-20$ & 71 & 23 & 129 \\
\hline $21-50$ & 53 & 13 & 66 \\
\hline $51-100$ & 37 & 6 & 13 \\
\hline $101-500$ & 46 & 10 & 76 \\
\hline $501-1000$ & 8 & 2 & 6 \\
\hline$>1000$ & 17 & 5 & 11 \\
\hline Missing number of employees & 239 & 27 & $\mathbf{5 0 1}$ \\
\hline Total & $\mathbf{5 4 9}$ & $\mathbf{1 1 5}$ & 79 \\
\hline & & No Official Evacuation Ordered \\
\hline 0 & 179 & 45 & 32 \\
\hline $1-5$ & 87 & 15 & 34 \\
\hline $6-20$ & 170 & 18 & 37 \\
\hline $21-50$ & 137 & 15 & 22 \\
\hline $51-100$ & 102 & 9 & 47 \\
\hline $101-500$ & 262 & 21 & 9 \\
\hline $501-1000$ & 53 & 4 & $\mathbf{5 6 0}$ \\
\hline$>1000$ & 186 & 7 & 91 \\
\hline Missing number of employees & 438 & $\mathbf{2 0 0}$ & \\
\hline Total & $\mathbf{1 , 6 1 4}$ & & \\
\hline
\end{tabular}

* Two incidents had a missing evacuation status 
Table 5. Number of transportation incidents, transportation incidents with injured persons/fatalities, and total number of injured people/fatalities by transportation stage, NTSIP 2011.

\begin{tabular}{|c|c|c|c|c|c|}
\hline \multirow[b]{3}{*}{ Transportation Stage } & \multicolumn{5}{|c|}{ NTSIP-eligible Transportation Incidents } \\
\hline & \multirow[b]{2}{*}{$\begin{array}{c}\text { Incidents } \\
\\
\text { \# of } \\
\text { Transportation } \\
\text { Incidents }\end{array}$} & \multicolumn{2}{|c|}{ Injuries } & \multicolumn{2}{|c|}{ Fatalities } \\
\hline & & $\begin{array}{c}\# \text { of } \\
\text { Transportation } \\
\text { Incidents } \\
\text { with Injured } \\
\text { People } \\
\end{array}$ & $\begin{array}{c}\text { Total \# } \\
\text { of } \\
\text { Injured } \\
\text { People } \\
\end{array}$ & $\begin{array}{c}\# \text { of } \\
\text { Transportation } \\
\text { Incidents } \\
\text { with Fatalities } \\
\end{array}$ & $\begin{array}{c}\text { Total \# } \\
\text { of } \\
\text { Fatalities }\end{array}$ \\
\hline $\begin{array}{l}\text { Occurred during unloading of a } \\
\text { stationary vehicle or vessel }\end{array}$ & 266 & 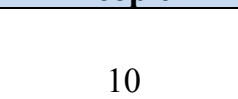 & 14 & 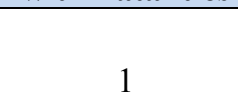 & 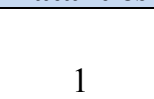 \\
\hline From a moving vehicle or vessel & 238 & 31 & 64 & 9 & 14 \\
\hline $\begin{array}{l}\text { En route and later discovered at a } \\
\text { fixed facility }\end{array}$ & 308 & 3 & 5 & 1 & 1 \\
\hline $\begin{array}{l}\text { Occurred from a stationary } \\
\text { vehicle or vessel }\end{array}$ & 107 & 13 & 26 & 5 & 5 \\
\hline Other & 44 & 4 & 6 & 0 & 0 \\
\hline Missing transportation route & 2 & 1 & 1 & 1 & 1 \\
\hline Total & 965 & 62 & 116 & 17 & 22 \\
\hline
\end{tabular}


Table 6. The Top 20 most common individual chemicals released in fixed facility NTSIP incidents, 2011.

\begin{tabular}{|c|c|c|c|}
\hline \multicolumn{4}{|c|}{ Top 20 Chemicals Involved in NTSIP-eligible Fixed Facility Incidents, 2011} \\
\hline Rank & Chemical Name & \# & $\begin{array}{l}\text { Percentage of Total Fixed } \\
\text { Facility Incidents }(\%)^{\mathrm{a}}\end{array}$ \\
\hline$(1)$ & Natural Gas & 329 & 15.2 \\
\hline (2) & Carbon Monoxide & 197 & 9.1 \\
\hline (3) & $\begin{array}{l}\text { Methamphetamine } \\
\text { Chemicals, NOS }\end{array}$ & 131 & 6.1 \\
\hline (4) & Ammonia & 104 & 4.8 \\
\hline (5) & Propane & 74 & 3.4 \\
\hline (6) & Mercury & 60 & 2.8 \\
\hline (7) & Chlorine & 53 & 2.5 \\
\hline (8) & Alkaline Hydroxide ${ }^{\mathrm{b}}$ & 50 & 2.3 \\
\hline (9) & Sulfuric Acid & 42 & 1.9 \\
\hline (10) & Hydrochloric Acid & 36 & 1.7 \\
\hline (11) & Sulfur Dioxide & 36 & 1.7 \\
\hline (12) & Sodium Hypochlorite & 24 & 1.1 \\
\hline (13) & Ethylene & 21 & 1.0 \\
\hline (14) & Benzene & 20 & 0.9 \\
\hline (15) & $\begin{array}{l}\text { Polychlorinated Biphenyls } \\
\text { (PCBs) }\end{array}$ & 18 & 0.8 \\
\hline (16) & Dimethylsiloxane & 18 & 0.8 \\
\hline (17) & Hydrogen Sulfide, NOS ${ }^{\mathrm{c}}$ & 18 & 0.8 \\
\hline (18) & Diesel Fuel & 15 & 0.7 \\
\hline (19) & Hydrogen Peroxide & 14 & 0.6 \\
\hline (20) & Chlorodifluoromethane & 13 & 0.6 \\
\hline \multicolumn{2}{|c|}{$\begin{array}{l}\text { Total number of incidents with Top } 20 \\
\text { chemicals involved in fixed facility incidents }\end{array}$} & 1,273 & 58.9 \\
\hline
\end{tabular}

\footnotetext{
${ }^{a}$ Percentages calculated on the basis of the total number of fixed facility incidents $(n=2,163)$

${ }^{\mathrm{b}}$ Alkaline hydroxide includes both sodium hydroxide and potassium hydroxide

${ }^{\mathrm{c}} \mathrm{NOS}=$ not otherwise specified
} 
Table 7. The Top 10 most common individual chemicals released in transportation NTSIP incidents, 2011.

\begin{tabular}{|c|c|c|c|}
\hline \multicolumn{4}{|c|}{ Top 10 Chemicals Involved in NTSIP-eligible Transportation Incidents, 2011} \\
\hline Rank & Chemical Name & \# & $\begin{array}{c}\text { Percentage of Total } \\
\text { Transportation Incidents }(\%)^{\mathrm{a}}\end{array}$ \\
\hline$(1)$ & Alkaline Hydroxide ${ }^{b}$ & 105 & 10.9 \\
\hline (2) & Hydrochloric Acid & 54 & 5.6 \\
\hline (3) & Sulfuric Acid & 48 & 5.0 \\
\hline (4) & Hydrogen Peroxide & 24 & 2.5 \\
\hline$(5)$ & Diesel Fuel & 16 & 1.7 \\
\hline (6) & Ink, NOS & 16 & 1.7 \\
\hline (7) & Resin, NOS & 16 & 1.7 \\
\hline$(8)$ & Flammable Liquid, NOS $^{\mathrm{c}}$ & 14 & 1.5 \\
\hline (9) & Natural Gas & 14 & 1.5 \\
\hline$(10)$ & $\begin{array}{l}\text { Methamphetamine } \\
\text { Chemicals, NOS }\end{array}$ & 11 & 1.1 \\
\hline $\begin{array}{l}\text { Total nu } \\
\text { chemic: }\end{array}$ & $\begin{array}{l}\text { f incidents with Top } 10 \\
\text { lved in transportation } \\
\text { ncidents }\end{array}$ & 318 & 33.2 \\
\hline
\end{tabular}

${ }^{a}$ Percentages calculated on the basis of the total number of transportation incidents $(n=965)$

${ }^{\mathrm{b}}$ Alkaline hydroxide includes both sodium hydroxide and potassium hydroxide

${ }^{\mathrm{c}} \mathrm{NOS}=$ not otherwise specified 
Table 9. Number and \% of injured people in NTSIP-eligible incidents by adverse health effects and type of incidents (fixed facility, transportation, and total) among those who are exposed to carbon monoxide.

\begin{tabular}{|l|c|c|}
\hline \multirow{2}{*}{$\begin{array}{l}\text { Adverse Health Effects from Exposure to } \\
\text { Carbon Monoxide }\end{array}$} & \multicolumn{2}{|c|}{$\begin{array}{c}\text { Number of Injured People in } \\
\text { NTSIP-eligible incidents }\end{array}$} \\
\cline { 2 - 3 } & \multicolumn{2}{|c|}{ Total } \\
\cline { 2 - 3 } $\begin{array}{l}\text { Trauma } \\
\text { Chemical-related }\end{array}$ & $\mathbf{2}$ & $\mathbf{0 . 8}$ \\
\hline Respiratory system problems & 2 & 100 \\
\hline Gastrointestinal problems & 17 & 6.6 \\
\hline Other & 1 & 0.4 \\
\hline Skin irritation & 2 & 0.8 \\
\hline Dizziness or other Central Nervous System & 1 & 0.4 \\
(CNS) symptoms & 145 & 56.6 \\
\hline Headache & & 2.3 \\
\hline Shortness of breath (unknown cause) & 6 & 2.0 \\
\hline TWO adverse health effects & 5 & 19.1 \\
\hline THREE adverse health effects & 49 & 10.9 \\
\hline Total \# of Injured People & 28 & $\mathbf{1 0 0}$ \\
\hline
\end{tabular}

*Note: total number of carbon monoxide incidents $(n=202)$

Table 10. Number and \% of injured people in NTSIP-eligible incidents by adverse health effects and type of incidents (fixed facility, transportation, and total) among those who are exposed to paints and dyes ${ }^{\mathrm{a}}$.

\begin{tabular}{|l|c|c|}
\hline \multirow{2}{*}{$\begin{array}{l}\text { Adverse Health Effects from Exposure to } \\
\text { Paints and Dyes }\end{array}$} & \multicolumn{2}{|c|}{$\begin{array}{c}\text { Number of Injured People in } \\
\text { NTSIP-eligible incidents }\end{array}$} \\
\cline { 2 - 3 } Total \\
\cline { 2 - 3 } $\begin{array}{c}\text { Trauma } \\
\text { Chemical-related }\end{array}$ & $\mathbf{1}$ & $\mathbf{1}$ \\
Not chemical-related & 0 & 0 \\
& 1 & $\mathbf{1 0 0}$ \\
\hline Respiratory system problems & & 72.1 \\
\hline Skin irritation & 44 & 1.3 \\
\hline Burns & 1 & $\mathbf{2 4 . 6}$ \\
$\quad$ Type not specified & $\mathbf{1 5}$ & 100 \\
\hline Total \# of Injured People & 15 & $\mathbf{1 0 0}$ \\
\hline
\end{tabular}

${ }^{\mathrm{a}}$ Total percentages do not equal 100 due to rounding

*When examining injuries resulting from NTSIP eligible incidents, it is necessary to keep in mind that those occurring through non-chemical related traumas and thermal burns were related to a fire or an accident, rather than from exposure to a chemical 
Table 11. The number of NTSIP-eligible incidents classified as petroleum and number of incidents (fixed facility, transportation, and total) attributed to each chemical name ${ }^{\mathrm{a}}$.

\begin{tabular}{|c|c|c|c|c|c|c|}
\hline \multirow[b]{3}{*}{ Chemical name } & \multicolumn{6}{|c|}{ NTSIP Eligible Incidents } \\
\hline & \multicolumn{2}{|c|}{ Fixed Facilities } & \multicolumn{2}{|c|}{ Transportation } & \multicolumn{2}{|c|}{ Total } \\
\hline & $\#$ & $\%$ & \# & $\%$ & \# & $\%$ \\
\hline Asphalt & 1 & 0.2 & 1 & 1.5 & 2 & 0.4 \\
\hline Asphalt NOS & 0 & 0 & 1 & 1.5 & 1 & 0.2 \\
\hline Asphalt Sealer & 1 & 0.2 & 1 & 1.5 & 2 & 0.4 \\
\hline Aviation Fuel NOS & 0 & 0 & 1 & 1.5 & 1 & 0.2 \\
\hline Butane & 2 & 0.4 & 2 & 3.0 & 4 & 0.8 \\
\hline Cationic Asphalt Emulsion Heavy & 1 & 0.2 & 0 & 0 & 1 & 0.2 \\
\hline Diesel Fuel & 15 & 3.2 & 16 & 24.2 & 31 & 5.8 \\
\hline Flammable Gas NOS & 7 & 1.5 & 0 & 0 & 7 & 1.3 \\
\hline Fuel & 0 & 0 & 1 & 1.5 & 1 & 0.2 \\
\hline Fuel NOS & 1 & 0.2 & 2 & 3.0 & 3 & 0.6 \\
\hline Fuel Oil NOS & 2 & 0.4 & 0 & 0 & 2 & 0.4 \\
\hline Gasoline & 11 & 2.4 & 9 & 13.6 & 20 & 3.8 \\
\hline Heat Transfer Oil & 0 & 0 & 1 & 1.5 & 1 & 0.2 \\
\hline Hydraulic Fluid & 0 & 0 & 1 & 1.5 & 1 & 0.2 \\
\hline Hydraulic Oil & 2 & 0.4 & 1 & 1.5 & 3 & 0.6 \\
\hline Jet Fuel & 0 & 0 & 1 & 1.5 & 1 & 0.2 \\
\hline Kerosene & 2 & 0.4 & 0 & 0 & 2 & 0.4 \\
\hline Liquefied Petroleum Gas & 1 & 0.2 & 1 & 1.5 & 2 & 0.4 \\
\hline Lube Oil & 0 & 0 & 1 & 1.5 & 1 & 0.2 \\
\hline Mineral Spirits & 0 & 0 & 1 & 1.5 & 1 & 0.2 \\
\hline Motor Oil & 1 & 0.2 & 0 & 0 & 1 & 0.2 \\
\hline Natural Gas & 329 & 70.5 & 14 & 21.2 & 343 & 64.4 \\
\hline Oil & 4 & 0.9 & 0 & 0 & 4 & 0.8 \\
\hline Petroleum Distillates & 2 & 0.4 & 0 & 0 & 2 & 0.4 \\
\hline Petroleum Product NOS & 1 & 0.2 & 0 & 0 & 1 & 0.2 \\
\hline Propane & 74 & 15.9 & 7 & 10.6 & 81 & 15.2 \\
\hline Roofing Asphalt Primer & 0 & 0 & 1 & 1.5 & 1 & 0.2 \\
\hline Transformer Oil & 8 & 1.7 & 0 & 0 & 8 & 1.5 \\
\hline Waste Oil & 2 & 0.4 & 1 & 1.5 & 3 & 0.6 \\
\hline Xylene & 0 & 0 & 2 & 3.0 & 2 & 0.4 \\
\hline Total & 467 & 100 & 66 & 100 & 533 & 100 \\
\hline
\end{tabular}

${ }^{\mathrm{a}}$ Total percentages do not equal 100 due to rounding 
Table 12. Number and \% of injured people in NTSIP-eligible incidents by adverse health effects and type of incidents (fixed facility, transportation, and total) among those who are exposed to petroleum.

\begin{tabular}{|c|c|c|}
\hline \multirow{3}{*}{$\begin{array}{l}\text { Adverse Health Effects from Exposure to } \\
\text { Petroleum }\end{array}$} & \multirow{2}{*}{\multicolumn{2}{|c|}{$\begin{array}{l}\text { Number of Injured People } \\
\text { in NTSIP-eligible incidents } \\
\text { Total } \\
\end{array}$}} \\
\hline & & \\
\hline & $\#$ & $\%$ \\
\hline Trauma & 48 & 23.4 \\
\hline Chemical-related & 4 & 8.3 \\
\hline Not chemical-related* & 35 & 72.9 \\
\hline Both & 9 & 18.3 \\
\hline Respiratory system problems & 16 & 7.8 \\
\hline Gastrointestinal problems & 2 & 1.0 \\
\hline Heat stress & 6 & 2.9 \\
\hline Burns & 67 & 32.7 \\
\hline Thermal & 53 & 79.1 \\
\hline Chemical & 7 & 10.5 \\
\hline Both & 7 & 10.5 \\
\hline Other & 2 & 1.0 \\
\hline Dizziness or other CNS symptoms & 31 & 15.1 \\
\hline Headache & 2 & 1.0 \\
\hline Shortness of breath (unknown cause) & 1 & 0.5 \\
\hline Two adverse health effects & 6 & 2.9 \\
\hline Three adverse health effects & 4 & 2.0 \\
\hline Missing adverse health effect & 20 & 9.8 \\
\hline Total \# of Injured People & 205 & 100 \\
\hline
\end{tabular}

*When examining injuries resulting from NTSIP eligible incidents, it is necessary to keep in mind that those occurring through other than chemical-related traumas and thermal burns should be separated because the injuries were related to a fire or an accident, rather than from exposure to a chemical 
Table 13. Number and percent of NTSIP-eligible incidents and injured people by primary contributing factors and type of incidents (fixed facility, transportation, and total), NTSIP $2011^{\mathrm{a}}$.

\begin{tabular}{|c|c|c|c|c|c|c|}
\hline \multirow[b]{3}{*}{ Primary Contributing Factor } & \multicolumn{6}{|c|}{ NTSIP-eligible Incidents } \\
\hline & \multicolumn{2}{|c|}{ Fixed Facilities } & \multicolumn{2}{|c|}{ Transportation } & \multicolumn{2}{|c|}{ Total } \\
\hline & \# & $\%$ & \# & $\%$ & \# & $\%$ \\
\hline Equipment failure & 1,104 & 51.0 & 252 & 26.1 & 1,356 & 43.3 \\
\hline Human error & 651 & 30.2 & 666 & 69.0 & 1,317 & 42.1 \\
\hline Other & 56 & 2.6 & 14 & 1.5 & 70 & 2.2 \\
\hline Intentional & 41 & 1.9 & 5 & 0.5 & 46 & 1.5 \\
\hline Bad weather condition/natural disasters & 53 & 2.5 & 3 & 0.3 & 56 & 1.8 \\
\hline Illegal act & 219 & 10.1 & 22 & 2.3 & 241 & 7.7 \\
\hline Missing primary contributing factor & 39 & 1.8 & 3 & 0.3 & 42 & 1.3 \\
\hline Total \# of NTSIP-eligible incidents & 2,163 & 100 & 965 & 100 & 3,128 & 100 \\
\hline \multirow[b]{3}{*}{ Primary Contributing Factor } & \multicolumn{6}{|c|}{ NTSIP-eligible Incidents-Injuries } \\
\hline & \multicolumn{2}{|c|}{ Fixed Facilities } & \multicolumn{2}{|c|}{ Transportation } & \multicolumn{2}{|c|}{ Total } \\
\hline & $\#$ & $\%$ & $\#$ & $\%$ & \# & $\%$ \\
\hline Equipment failure & 423 & 39.9 & 25 & 21.6 & 448 & 38.1 \\
\hline Human error & 245 & 23.1 & 76 & 65.5 & 421 & 35.8 \\
\hline Other & 39 & 3.7 & 1 & 0.9 & 40 & 3.4 \\
\hline Intentional & 35 & 3.3 & 5 & 4.3 & 40 & 3.4 \\
\hline Bad weather condition/natural disasters & 16 & 1.5 & 1 & 0.9 & 17 & 1.4 \\
\hline Illegal act & 110 & 10.4 & 5 & 4.3 & 115 & 9.8 \\
\hline Missing primary contributing factor & 93 & 8.8 & 3 & 2.6 & 96 & 8.2 \\
\hline Total \# of Injured People & 1,061 & 100 & 116 & 100 & 1,177 & 100 \\
\hline
\end{tabular}

${ }^{\mathrm{a}}$ Total percentages do not equal 100 due to rounding 
Table 14. Number and percent of NTSIP-eligible incidents by secondary contributing factors and type of incidents (fixed facility, transportation, and total), NTSIP 2011 $1^{\mathrm{a}}$.

\begin{tabular}{|l|c|c|c|c|c|c|}
\hline \multirow{2}{*}{ Secondary Contributing Factor } & \multicolumn{4}{|c|}{ NTSIP-eligible Incidents } \\
\cline { 2 - 7 } & \multicolumn{2}{|c|}{ Fixed Facilities } & \multicolumn{2}{c|}{ Transportation } & \multicolumn{2}{c|}{ Total } \\
\cline { 2 - 7 } & $\#$ & $\mathbf{\%}$ & $\#$ & \multicolumn{1}{c|}{$\#$} & \multicolumn{1}{c|}{ \% } \\
\hline Equipment failure & 258 & 11.9 & 162 & 16.8 & 420 & 13.4 \\
\hline Human error & 20 & 0.9 & 45 & 4.7 & 65 & 2.1 \\
\hline Other & 59 & 2.7 & 1 & 0.1 & 60 & 1.9 \\
\hline Intentional & 2 & 0.1 & 0 & 0 & 2 & 0.1 \\
\hline Bad weather condition/natural disasters & 5 & 0.2 & 2 & 0.2 & 7 & 0.2 \\
\hline Illegal act & 13 & 0.6 & 2 & 0.2 & 15 & 0.5 \\
\hline No secondary factor & 1,622 & 75.0 & 662 & 68.6 & 2,284 & 73.0 \\
\hline Missing secondary contributing factor & 184 & 8.5 & 91 & 9.4 & 275 & 8.8 \\
\hline Total \# of NTSIP-eligible incidents & $\mathbf{2 , 1 6 3}$ & $\mathbf{1 0 0}$ & $\mathbf{9 6 5}$ & $\mathbf{1 0 0}$ & $\mathbf{3 , 1 2 8}$ & $\mathbf{1 0 0}$ \\
\hline
\end{tabular}

${ }^{\text {a }}$ Total percentages do not equal 100 due to rounding 
Table 15. Number and percent of NTSIP-eligible incidents and injured people in NTSIP-eligible incidents by specific primary supplemental factors and type of incidents (fixed facility, transportation, and total), NTSIP 2011 $1^{\mathrm{a}}$.

\begin{tabular}{|c|c|c|c|c|c|c|}
\hline \multirow[b]{3}{*}{ Primary Supplemental Factor } & \multicolumn{6}{|c|}{ NTSIP-eligible Incidents } \\
\hline & \multicolumn{2}{|c|}{ Fixed Facilities } & \multicolumn{2}{|c|}{ Transportation } & \multicolumn{2}{|c|}{ Total } \\
\hline & $\#$ & $\%$ & \# & $\%$ & \# & $\%$ \\
\hline Improper mixing & 42 & 1.9 & 2 & 0.2 & 44 & 1.4 \\
\hline Improper filling, loading, or packing & 103 & 4.8 & 450 & 46.6 & 553 & 17.7 \\
\hline Other & 534 & 24.7 & 190 & 19.7 & 724 & 23.2 \\
\hline Performing maintenance & 42 & 1.9 & 2 & 0.2 & 44 & 1.4 \\
\hline System/process upset & 164 & 7.6 & 28 & 2.9 & 192 & 6.1 \\
\hline System start up and shut down & 24 & 1.1 & 3 & 0.3 & 27 & 0.9 \\
\hline Power failure/electrical problems & 29 & 1.3 & 0 & 0 & 29 & 0.9 \\
\hline Unauthorized/improper dumping & 15 & 0.7 & 1 & 0.1 & 16 & 0.5 \\
\hline Vehicle or vessel collision & 17 & 0.8 & 41 & 4.3 & 58 & 1.9 \\
\hline Fire & 156 & 7.2 & 12 & 1.3 & 168 & 5.4 \\
\hline Explosion & 78 & 3.6 & 3 & 0.3 & 81 & 2.6 \\
\hline Overspray/misapplication & 50 & 2.3 & 7 & 0.7 & 57 & 1.8 \\
\hline Loadshift & 3 & 0.1 & 18 & 1.9 & 21 & 0.7 \\
\hline Vehicle or vessel derailment/rollover/capsizing & 2 & 0.1 & 56 & 5.8 & 58 & 1.9 \\
\hline Illicit drug production-related & 180 & 8.3 & 20 & 2.1 & 200 & 6.4 \\
\hline Forklift puncture & 55 & 2.5 & 41 & 4.3 & 96 & 3.1 \\
\hline Vandalism & 12 & 0.6 & 2 & 0.2 & 14 & 0.4 \\
\hline Missing primary supplemental factor & 657 & 30.4 & 89 & 9.2 & 746 & 23.8 \\
\hline Total \# of NTSIP-eligible incidents & 2,163 & 100 & 965 & 100 & 3,128 & 100 \\
\hline \multirow[b]{3}{*}{ Primary Supplemental Factor } & \multicolumn{6}{|c|}{ NTSIP-eligible Incidents-Injuries } \\
\hline & \multicolumn{2}{|c|}{ Fixed Facilities } & \multicolumn{2}{|c|}{ Transportation } & \multicolumn{2}{|c|}{ Total } \\
\hline & $\#$ & $\%$ & $\#$ & $\%$ & $\#$ & $\%$ \\
\hline Improper mixing & 110 & 10.4 & 1 & 0.9 & 111 & 9.4 \\
\hline Improper filling, loading, or packing & 5 & 0.5 & 6 & 5.2 & 11 & 0.9 \\
\hline Other & 119 & 11.2 & 14 & 12.1 & 132 & 11.9 \\
\hline Performing maintenance & 27 & 2.5 & 0 & 0 & 27 & 2.3 \\
\hline System/process upset & 42 & 4.0 & 3 & 2.6 & 45 & 3.8 \\
\hline System start up and shut down & 3 & 0.3 & 2 & 1.7 & 5 & 0.4 \\
\hline Power failure/electrical problems & 15 & 1.4 & 0 & 0 & 15 & 1.3 \\
\hline Unauthorized/improper dumping & 7 & 0.7 & 0 & 0 & 7 & 0.6 \\
\hline Vehicle or vessel collision & 5 & 0.5 & 32 & 27.6 & 37 & 3.1 \\
\hline Fire & 91 & 8.6 & 5 & 4.3 & 96 & 8.2 \\
\hline Explosion & 165 & 15.6 & 3 & 2.6 & 168 & 14.3 \\
\hline Overspray/misapplication & 53 & 5.0 & 0 & 0 & 53 & 4.5 \\
\hline Loadshift & 0 & 0 & 1 & 0.9 & 1 & 0.1 \\
\hline Vehicle or vessel derailment/rollover/capsizing & 1 & 0.1 & 18 & 15.5 & 19 & 1.6 \\
\hline Illicit drug production-related & 64 & 6.0 & 3 & 2.6 & 67 & 5.7 \\
\hline Forklift puncture & 2 & 0.2 & 0 & 0 & 2 & 0.2 \\
\hline Vandalism & 2 & 0.2 & 3 & 2.6 & 5 & 0.4 \\
\hline Missing primary supplemental factor & 350 & 33.0 & 25 & 21.6 & 375 & 31.9 \\
\hline Total \# of Injured People & 1,061 & 100 & 116 & 100 & 1,177 & 100 \\
\hline
\end{tabular}


Table 16. Number and percent of NTSIP-eligible incidents in NTSIP-eligible incidents by specific secondary supplemental factors and type of incidents (fixed facility, transportation, and total), NTSIP 2011 ${ }^{\mathrm{a}}$.

\begin{tabular}{|l|c|c|c|c|c|c|}
\hline \multirow{2}{*}{ Secondary Supplemental Factor } & \multicolumn{9}{|c|}{ NTSIP-eligible Incidents } \\
\cline { 2 - 7 } & \multicolumn{2}{|c|}{ Fixed Facilities } & \multicolumn{2}{c|}{ Transportation } & \multicolumn{3}{c|}{ Total } \\
\cline { 2 - 7 } & $\#$ & $\mathbf{\%}$ & $\#$ & $\mathbf{\%}$ & $\#$ & $\mathbf{\%}$ \\
\hline Improper filling, loading, or packing & 1 & 0.05 & 3 & 0.3 & 4 & 0.1 \\
\hline Other & 38 & 1.8 & 63 & 6.5 & 101 & 3.2 \\
\hline Performing maintenance & 1 & 0.05 & 1 & 0.1 & 2 & 0.1 \\
\hline System/process upset & 8 & 0.4 & 4 & 0.4 & 12 & 0.4 \\
\hline System start up and shut down & 2 & 0.1 & 0 & 0 & 2 & 0.1 \\
\hline Power failure/electrical problems & 2 & 0.1 & 0 & 0 & 2 & 0.1 \\
\hline Fire & 47 & 2.2 & 6 & 0.6 & 53 & 1.7 \\
\hline Explosion & 45 & 2.1 & 6 & 0.6 & 51 & 1.6 \\
\hline Loadshift & 2 & 0.1 & 24 & 2.5 & 26 & 0.8 \\
\hline Vehicle or vessel derailment/rollover/capsizing & 1 & 0.05 & 2 & 0.2 & 3 & 0.1 \\
\hline Forklift puncture & 2 & 0.1 & 2 & 0.2 & 4 & 0.1 \\
\hline Missing secondary supplemental factor & 392 & 18.1 & 192 & 19.9 & 584 & 18.7 \\
\hline No secondary supplemental factor & $\mathbf{1 . 6 2 2}$ & $\mathbf{7 5 . 0}$ & $\mathbf{6 6 2}$ & $\mathbf{6 8 . 6}$ & $\mathbf{2 , 2 8 4}$ & $\mathbf{7 3 . 0}$ \\
\hline Total \# of NTSIP-eligible incidents & $\mathbf{2 , 1 6 3}$ & $\mathbf{1 0 0}$ & $\mathbf{9 6 5}$ & $\mathbf{1 0 0}$ & $\mathbf{3 , 1 2 8}$ & $\mathbf{1 0 0}$ \\
\hline
\end{tabular}

${ }^{\text {a }}$ Total percentages do not equal 100 due to rounding

Table 17. Number of NTSIP-eligible incidents and total number of injured people by number of injured people per incident and type of incidents (fixed facility, transportation, and total), NTSIP 2011.

\begin{tabular}{|c|c|c|c|c|c|c|}
\hline \multirow[b]{3}{*}{$\begin{array}{l}\text { \# of Injured } \\
\text { People per } \\
\text { Incident }\end{array}$} & \multicolumn{6}{|c|}{ NTSIP-eligible Incidents } \\
\hline & \multicolumn{2}{|c|}{ Fixed Facility } & \multicolumn{2}{|c|}{ Transportation } & \multicolumn{2}{|c|}{ Total } \\
\hline & \# of incidents & $\begin{array}{l}\text { Total \# of } \\
\text { injured } \\
\text { persons }\end{array}$ & \# of incidents & $\begin{array}{l}\text { Total \# of } \\
\text { injured } \\
\text { persons }\end{array}$ & \# of incidents & $\begin{array}{l}\text { Total \# of } \\
\text { injured } \\
\text { persons }\end{array}$ \\
\hline None & 1,760 & 0 & 903 & 0 & 2,663 & 0 \\
\hline Any: & 404 & 1,069 & 62 & 116 & 466 & 1,185 \\
\hline 1 person & 235 & 235 & 39 & 39 & 274 & 274 \\
\hline 2 persons & 56 & 112 & 14 & 28 & 70 & 140 \\
\hline 3 persons & 36 & 108 & 5 & 15 & 41 & 123 \\
\hline 4 persons & 22 & 88 & 1 & 4 & 23 & 92 \\
\hline 5 persons & 19 & 95 & 0 & 0 & 19 & 95 \\
\hline $6+$ persons & 35 & 422 & 3 & 30 & 38 & 452 \\
\hline Total & 2,163 & 1,061 & 965 & 116 & 3,128 & $\mathbf{1 , 1 7 7}$ \\
\hline
\end{tabular}


Table 18. Number and percent of injured people in NTSIP-eligible incidents by severity and disposition of injured people and type of incidents (fixed facility, transportation, and total), NTSIP 2011.

\begin{tabular}{|l|c|c|c|c|c|c|}
\hline \multirow{2}{*}{$\begin{array}{l}\text { Severity and Disposition of Injured } \\
\text { People }\end{array}$} & \multicolumn{6}{|c|}{ Number of Injured People in NTSIP-eligible incidents } \\
\cline { 2 - 7 } & \multicolumn{2}{|c|}{ Fixed Facility } & \multicolumn{2}{|c|}{ Transportation } & \multicolumn{3}{c|}{ Total } \\
\cline { 2 - 7 } & $\#$ & $\mathbf{\%}$ & $\#$ & $\mathbf{\%}$ & $\#$ & $\mathbf{\%}$ \\
\hline Treated on scene (first aid) & 143 & 13.5 & 10 & 8.6 & 153 & 13.0 \\
\hline Treated at hospital (not admitted) & 651 & 61.4 & 31 & 26.7 & 682 & 57.9 \\
\hline Treated at hospital (admitted) & 160 & 15.1 & 40 & 34.4 & 200 & 17.0 \\
\hline Observation at hospital; no treatment & 3 & 0.3 & 1 & 0.9 & 4 & 0.3 \\
\hline Seen by private physician within 24 hours & 6 & 0.6 & 0 & 0 & 6 & 0.5 \\
\hline $\begin{array}{l}\text { Injuries experienced within 24 hours of } \\
\text { incident and reported by official (e.g., fire } \\
\text { department, EMT) }\end{array}$ & & & & & & \\
\hline Death on scene/on arrival at hospital & 51 & 4.8 & 10 & 8.6 & 61 & 5.2 \\
\hline Death after arrival at hospital & 7 & 3.1 & 22 & 19.0 & 55 & 4.7 \\
\hline Missing severity/disposition & 7 & 0.7 & 0 & 0 & 7 & 0.6 \\
\hline Total \# of Injured People & $\mathbf{1 , 0 6 1}$ & $\mathbf{1 0 0}$ & $\mathbf{1 1 6}$ & $\mathbf{1 0 0}$ & $\mathbf{1 , 1 7 7}$ & $\mathbf{1 0 0}$ \\
\hline
\end{tabular}

Table 19. Number and percent of injured people in NTSIP-eligible incidents by category of injured people and type of incidents (fixed facility, transportation, and total), NTSIP $2011^{\mathrm{a}}$.

\begin{tabular}{|c|c|c|c|c|c|c|}
\hline \multirow[b]{3}{*}{ Category of Injured People } & \multicolumn{6}{|c|}{ Number of Injured People in NTSIP-eligible incidents } \\
\hline & \multicolumn{2}{|c|}{ Fixed Facility } & \multicolumn{2}{|c|}{ Transportation } & \multicolumn{2}{|c|}{ Total } \\
\hline & \# & $\%$ & \# & $\%$ & $\#$ & $\%$ \\
\hline Missing & 1 & 0.1 & 1 & 0.9 & 2 & 0.2 \\
\hline \multicolumn{7}{|l|}{ Employee } \\
\hline Employee & 317 & 29.9 & 48 & 41.4 & 365 & 31.0 \\
\hline \multicolumn{7}{|l|}{ Public } \\
\hline General public & 540 & 50.9 & 63 & 54.3 & 603 & 51.2 \\
\hline Student (at school) & 40 & 3.8 & 0 & 0 & 40 & 3.4 \\
\hline \multicolumn{7}{|l|}{ Responders/hospital personnel } \\
\hline Responder (not specified) & 9 & 0.8 & 0 & 0 & 9 & 0.8 \\
\hline Career firefighter & 99 & 9.3 & 2 & 1.7 & 101 & 8.5 \\
\hline Volunteer Firefighter & 19 & 1.8 & 0 & 0 & 19 & 1.6 \\
\hline Firefighter (not specified) & 20 & 1.9 & 1 & 0.9 & 21 & 1.8 \\
\hline Police officer & 12 & 1.1 & 1 & 0.9 & 13 & 1.1 \\
\hline EMT personnel & 1 & 0.1 & 0 & 0 & 1 & 0.1 \\
\hline $\begin{array}{l}\text { Employee is a member of company } \\
\text { response team }\end{array}$ & 3 & 0.3 & 0 & 0 & 3 & 0.3 \\
\hline Total \# of Injured People & 1,061 & 100 & 116 & 100 & 1,177 & 100 \\
\hline
\end{tabular}

${ }^{a}$ Total percentages do not equal 100 due to rounding 
Table 20. Number of injured people in NTSIP-eligible incidents by category of injured people and gender and age, NTSIP 2011.

\begin{tabular}{|l|c|c|c|c|c|c|}
\hline \multirow{2}{*}{ Category of Injured People } & \multicolumn{5}{|c|}{ Number of Injured People in NTSIP-eligible incidents } \\
\cline { 2 - 7 } & \multicolumn{7}{|c|}{ Gender } & \multicolumn{3}{c|}{ Age Category } \\
\cline { 2 - 7 } Missing & Male & Female & Missing & Child* & Adult** & Missing \\
\hline Employee & 2 & 0 & 0 & 0 & 2 & 0 \\
\hline Employee & & & & & & 21 \\
\hline Public & & 48 & 131 & 2 & 342 & \\
\hline General public & 230 & 151 & 222 & 104 & 391 & 108 \\
\hline Student (at school) & 7 & 7 & 26 & 35 & 5 & 0 \\
\hline Responders/hospital personnel & & & & & & \\
\hline Responder (not specified) & 2 & 0 & 7 & 0 & 8 & 1 \\
\hline Career firefighter & 82 & 3 & 16 & 0 & 101 & 0 \\
\hline Volunteer firefighter & 19 & 0 & 0 & 0 & 19 & 0 \\
\hline Firefighter (not specified) & 13 & 2 & 6 & 0 & 21 & 0 \\
\hline Police officer & 6 & 0 & 7 & 0 & 13 & 0 \\
\hline EMT personnel & 1 & 0 & 0 & 0 & 1 & 0 \\
\hline $\begin{array}{l}\text { Employee is member of company } \\
\text { response team }\end{array}$ & 0 & 1 & 2 & 0 & 1 & 2 \\
\hline Total \# of Injured People & $\mathbf{5 4 8}$ & $\mathbf{2 1 2}$ & $\mathbf{4 1 7}$ & $\mathbf{1 4 1}$ & $\mathbf{9 0 4}$ & $\mathbf{1 3 2}$ \\
\hline
\end{tabular}

"Child: under 18 years old

** Adult: 18 years old or greater 
Table 21. Number and percent of injured people in NTSIP-eligible incidents by adverse health effects and type of incidents (fixed facility, transportation, and total), NTSIP $2011^{\mathrm{a}}$.

\begin{tabular}{|c|c|c|c|c|c|c|}
\hline \multirow[b]{3}{*}{ Adverse Health Effects } & \multicolumn{6}{|c|}{ Total \# of Injured People in NTSIP incidents } \\
\hline & \multicolumn{2}{|c|}{ Fixed Facilities } & \multicolumn{2}{|c|}{ Transportation } & \multicolumn{2}{|c|}{ Total } \\
\hline & \# & $\%$ & \# & $\%$ & \# & $\%$ \\
\hline Trauma & 87 & 8.2 & 48 & 41.4 & 135 & 11.5 \\
\hline Chemical-related & 28 & 32.2 & 1 & 2.1 & 29 & 21.5 \\
\hline Not chemical-related* & 55 & 63.2 & 42 & 87.5 & 97 & 71.9 \\
\hline Both & 4 & 4.6 & 5 & 10.4 & 9 & 6.7 \\
\hline Respiratory system problems & 245 & 23.1 & 11 & 9.5 & 256 & 21.8 \\
\hline Eye irritation & 34 & 3.2 & 4 & 3.5 & 38 & 3.2 \\
\hline Gastrointestinal problems & 8 & 0.8 & 0 & 0 & 8 & 0.7 \\
\hline Heat stress & 7 & 0.7 & 0 & 0 & 7 & 0.6 \\
\hline Burns & 135 & 12.6 & 19 & 16.4 & 154 & 13.1 \\
\hline Thermal* & 72 & 53.3 & 8 & 42.1 & 80 & 51.9 \\
\hline Chemical & 36 & 26.7 & 10 & 52.6 & 46 & 29.9 \\
\hline Both & 21 & 15.6 & 1 & 5.3 & 22 & 14.3 \\
\hline Missing & 6 & 4.4 & 0 & 0 & 6 & 3.9 \\
\hline Other & 10 & 0.9 & 2 & 1.7 & 12 & 1.0 \\
\hline Skin irritation & 12 & 1.1 & 2 & 1.7 & 14 & 1.2 \\
\hline Dizziness or other CNS symptoms & 190 & 17.9 & 18 & 15.5 & 208 & 17.7 \\
\hline Headache & 14 & 1.3 & 1 & 0.9 & 15 & 1.3 \\
\hline Shortness of breath (unknown cause) & 19 & 1.8 & 3 & 2.6 & 22 & 1.9 \\
\hline TWO adverse health effects & 161 & 15.2 & 5 & 4.3 & 166 & 14.1 \\
\hline THREE adverse health effects & 98 & 9.2 & 2 & 1.7 & 100 & 8.5 \\
\hline More than THREE adverse health effects & 2 & 0.2 & 0 & 0 & 2 & 0.2 \\
\hline Missing adverse health effect & 39 & 3.7 & 1 & 0.9 & 40 & 3.4 \\
\hline Total \# of Injured People & 1,061 & 100 & 116 & 100 & 1,177 & 100 \\
\hline
\end{tabular}

${ }^{\mathrm{a}}$ Total percentages do not equal 100 due to rounding

*When examining injuries resulting from NTSIP eligible incidents, it is necessary to keep in mind that those occurring through non-chemical related traumas and thermal burns should be separated because the injuries were related to a fire or an accident, rather than from exposure to a chemical 
Table 22. Number and percent of NTSIP-eligible incidents by main type of responders and type of incidents (fixed facility, transportation, and total), NTSIP $2011^{\mathrm{a}}$.

\begin{tabular}{|l|c|c|c|c|c|c|}
\hline \multirow{2}{*}{ Type of responders } & \multicolumn{6}{|c|}{ Number of NTSIP-eligible incidents } \\
\cline { 2 - 7 } & \multicolumn{2}{|c|}{ Fixed Facilities } & \multicolumn{2}{c|}{ Transportation } & \multicolumn{2}{c|}{ Total } \\
\cline { 2 - 7 } & $\#$ & $\mathbf{\%}$ & $\#$ & $\mathbf{\%}$ & $\#$ & $\mathbf{\%}$ \\
\hline No response & 55 & 2.5 & 67 & 6.9 & 122 & 3.9 \\
\hline Certified HazMat team & 16 & 0.7 & 14 & 1.5 & 30 & 1.0 \\
\hline Company response team & 715 & 33.0 & 557 & 57.7 & 1,272 & 40.6 \\
\hline Law enforcement agency & 94 & 4.3 & 20 & 2.1 & 114 & 3.6 \\
\hline Fire department & 128 & 5.9 & 14 & 1.5 & 142 & 4.5 \\
\hline EMS & 3 & 0.1 & 0 & 0 & 3 & 0.1 \\
\hline Other & 7 & 0.3 & 1 & 0.1 & 8 & 0.3 \\
\hline Health department/health agency & 4 & 0.2 & 0 & 0 & 4 & 0.1 \\
\hline Environmental agency/EPA response team & 17 & 0.8 & 4 & 0.4 & 21 & 0.7 \\
\hline $3^{\text {rd } \text { Party clean-up contractor }}$ & 40 & 1.8 & 45 & 4.7 & 85 & 2.7 \\
\hline $\begin{array}{l}\text { Department of works/utilities/transportation } \\
\text { (includes Coast Guard) }\end{array}$ & & & & & & \\
\hline $\begin{array}{l}\text { State, county, or local emergency } \\
\text { manager/coordinators/planning committees }\end{array}$ & 13 & 0.6 & 2 & 0.2 & 15 & 0.5 \\
\hline Hospital & 2 & 0.1 & 0 & 0 & 2 & 0.1 \\
\hline Poison Center & 11 & 0.5 & 0 & 0 & 11 & 0.4 \\
\hline Two types of responders & 637 & 29.4 & 114 & 11.8 & 751 & 24.0 \\
\hline Three types of responders & 270 & 12.5 & 54 & 5.6 & 324 & 10.4 \\
\hline More than Three types of responders & 104 & 4.8 & 67 & 6.9 & 172 & 5.5 \\
\hline Missing responder types & 5 & 0.2 & 5 & 0.5 & 10 & 0.3 \\
\hline Total \# of NTSIP-eligible incidents & $\mathbf{2 , 1 6 3}$ & $\mathbf{1 0 0}$ & $\mathbf{9 6 5}$ & $\mathbf{1 0 0}$ & $\mathbf{3 , 1 2 8}$ & $\mathbf{1 0 0}$ \\
\hline
\end{tabular}

${ }^{\mathrm{a}}$ Total percentages do not equal 100 due to rounding 
Table 23. Type of industries (listed by NAICS code) involved in NTSIP-eligible incidents and injuries, NTSIP $2011^{\mathrm{a}}$.

\begin{tabular}{|c|c|c|c|c|}
\hline \multirow{3}{*}{ 2-Digit NAICS Classification Code } & \multicolumn{4}{|c|}{ NTSIP-eligible Incidents } \\
\hline & \multicolumn{2}{|c|}{ Incidents } & \multicolumn{2}{|c|}{ Injuries } \\
\hline & $\#$ & $\%^{\mathrm{a}}$ & \# & $\%^{a}$ \\
\hline 11-Agriculture, Forestry, Fishing, and Hunting & 51 & 1.6 & 8 & 0.7 \\
\hline 21-Mining & 28 & 0.9 & 4 & 0.3 \\
\hline 22-Utilities & 187 & 6.0 & 10 & 0.8 \\
\hline 23-Construction & 30 & 1.0 & 65 & 5.5 \\
\hline $\begin{array}{l}\text { 31-Manufacturing (includes food, beverage, tobacco, textile } \\
\text { and apparel, leather and allied product manufacturing) }\end{array}$ & 64 & 2.0 & 4 & 0.3 \\
\hline $\begin{array}{l}\text { 32-Manufacturing (includes wood, paper, printing, } \\
\text { petroleum and coal, chemical, plastic and rubber, and non- } \\
\text { metallic mineral manufacturing) }\end{array}$ & 454 & 14.5 & 38 & 3.2 \\
\hline $\begin{array}{l}\text { 33-Manufacturing (includes metal, machinery, electronics, } \\
\text { appliances, transportation equipment, furniture, and } \\
\text { miscellaneous manufacturing) }\end{array}$ & 52 & 1.7 & 33 & 2.8 \\
\hline 42-Wholesale Trade & 112 & 3.6 & 23 & 2.0 \\
\hline $\begin{array}{l}\text { 44-Retail Trade (includes motor vehicle, furniture and home } \\
\text { furnishings, electronics and appliances, building materials and } \\
\text { garden equipment, food and beverages, health and personal } \\
\text { care, gasoline, and clothing and accessories) }\end{array}$ & 42 & 1.3 & 17 & 1.4 \\
\hline $\begin{array}{l}\text { 45-Retail Trade (includes sporting goods, hobby, book and } \\
\text { music supplies, general merchandise, and miscellaneous) }\end{array}$ & 19 & 0.6 & 10 & 0.8 \\
\hline $\begin{array}{l}\text { 48-Transportation and Warehousing (includes transportation } \\
\text { by air, rail, water, truck, transit, and ground passenger, } \\
\text { pipeline, scenic and sightseeing, and transportation support } \\
\text { activities) }\end{array}$ & 799 & 25.5 & 30 & 2.5 \\
\hline $\begin{array}{l}\text { 49-Transportation and Warehousing (includes postal } \\
\text { service, couriers) }\end{array}$ & 103 & 3.3 & 2 & 0.2 \\
\hline 51-Information & 8 & 0.3 & 70 & 5.9 \\
\hline 52-Finance and Insurance & 7 & 0.2 & 9 & 0.8 \\
\hline 53-Real Estate and Rental Leasing & 189 & 6.0 & 119 & 10.1 \\
\hline 54-Professional, Scientific, and Technical Services & 26 & 0.8 & 14 & 1.2 \\
\hline 55-Management of Companies and Enterprises & 2 & 0.1 & 0 & 0 \\
\hline $\begin{array}{l}\text { 56-Administrative, Support, Waste Management and } \\
\text { Remediation Services }\end{array}$ & 54 & 1.7 & 7 & 0.6 \\
\hline 61-Educational Services & 77 & 2.5 & 76 & 6.5 \\
\hline 62-Health Care and Social Assistance & 44 & 1.4 & 35 & 3.0 \\
\hline 71-Arts, Entertainment and Recreation & 20 & 0.6 & 48 & 4.1 \\
\hline 72-Accommodation and Food Services & 37 & 1.2 & 56 & 4.8 \\
\hline 81 -Other Services & 46 & 1.5 & 43 & 3.7 \\
\hline 92-Public Administration & 35 & 1.1 & 43 & 3.7 \\
\hline No NAICS Industry Code (Vehicle or Residence) & 484 & 15.5 & 327 & 27.8 \\
\hline Not Identified & 46 & 1.5 & 48 & 4.1 \\
\hline Not an Industry or residence/vehicle & 112 & 3.6 & 38 & 3.2 \\
\hline Total & 3,128 & 100 & 1,177 & 100 \\
\hline
\end{tabular}

${ }^{a}$ Total percentages do not equal 100 due to rounding 


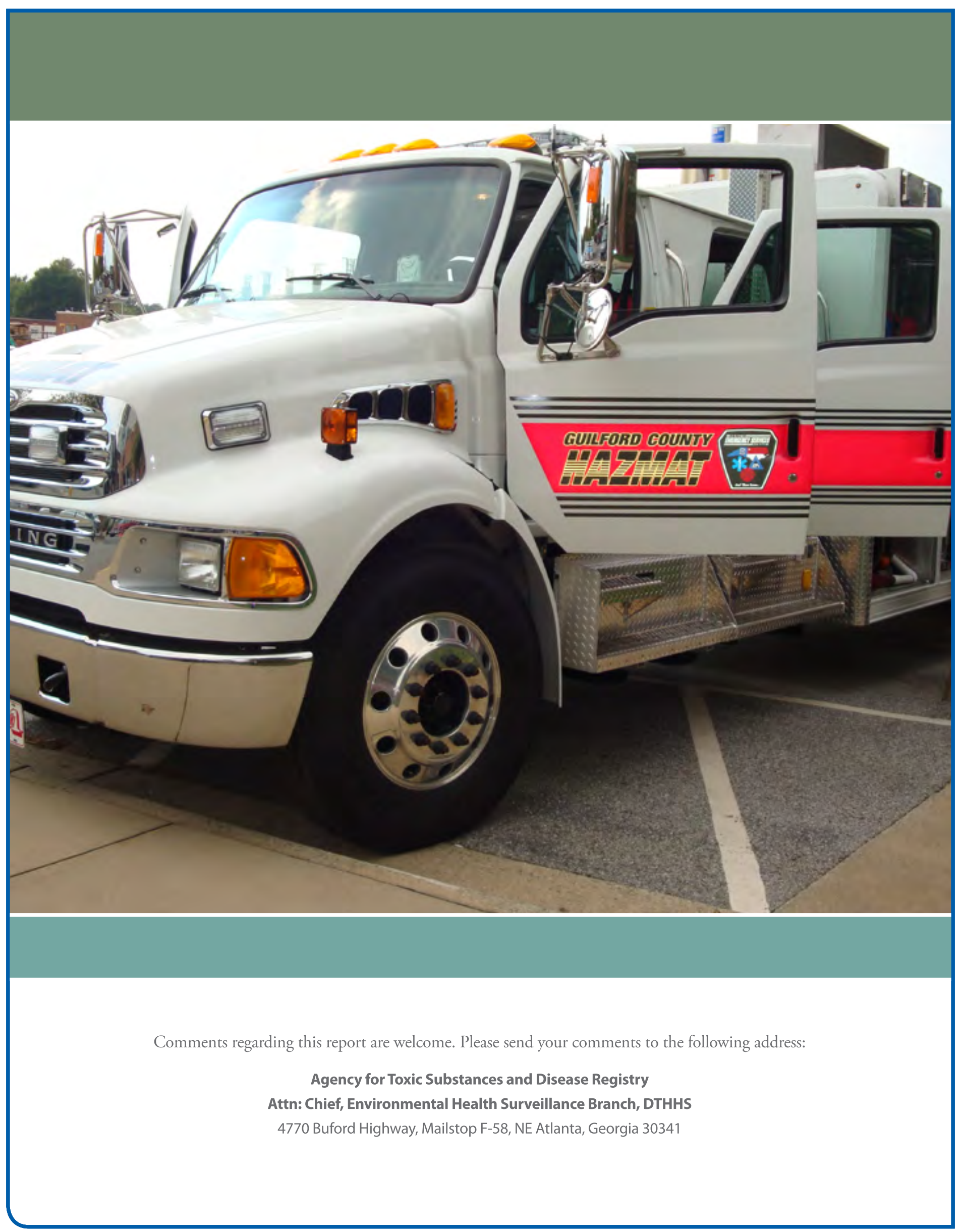

